\title{
INTEGRATING OF NANO ARCHITECTURE AND SUSTAINABILITY TOWARDS A BETTER BUILT ENVIRONMENT
}

\author{
Alaa-aldien Alsaied Farid ${ }^{1}$, Ahmed Hamed El-Sayed salama ${ }^{2}$ and Rania Said Sayd \\ Mourad $^{3}$ \\ ${ }^{1}$ Department of Architecture, Engineering, Faculty of Engineering, Al-Azhar University \\ University \\ ${ }^{2}$ Department of Civil, Engineering, Faculty of Engineering, Al-Azhar University University \\ ${ }^{3}$ Architect, Development, Research \& Studies Department Fund, Ministry of Housing
}

\begin{abstract}
ABASTRACT
The research study mechanism of achieving sustainable design and its principles which are (Economy of Resources - Sustainable Life Cycle for Buildings- Humane Design) And taking advantage of the latest technological tools such as nanotechnology to achieve the sustainability of the 21 st century.

The research also dealt with the applications of nanotechnology at architecture which crystallized by the full integration of architectural thought, its reflected on the methods of architecture design, in addition to the integration with all construction and non-construction materials, as a result of that we have got a new materials more solid, tough compared to conventional materials, as well as the role of nanotechnology at thriftiness Energy and its production.

The integration of nanotechnology with building materials has given us an opportunity to achieve comprehensive sustainability. Several trends have emerged supporting the use of Nano material for promote sustainability, such as biological architecture, ecological architecture and intelligent nanostructures. These trends represent a perfect harmony between sustainable design and nanotechnology! Which promises promising future prospects for the construction industry to acquire the sustainability of buildings for a better built environment.
\end{abstract}

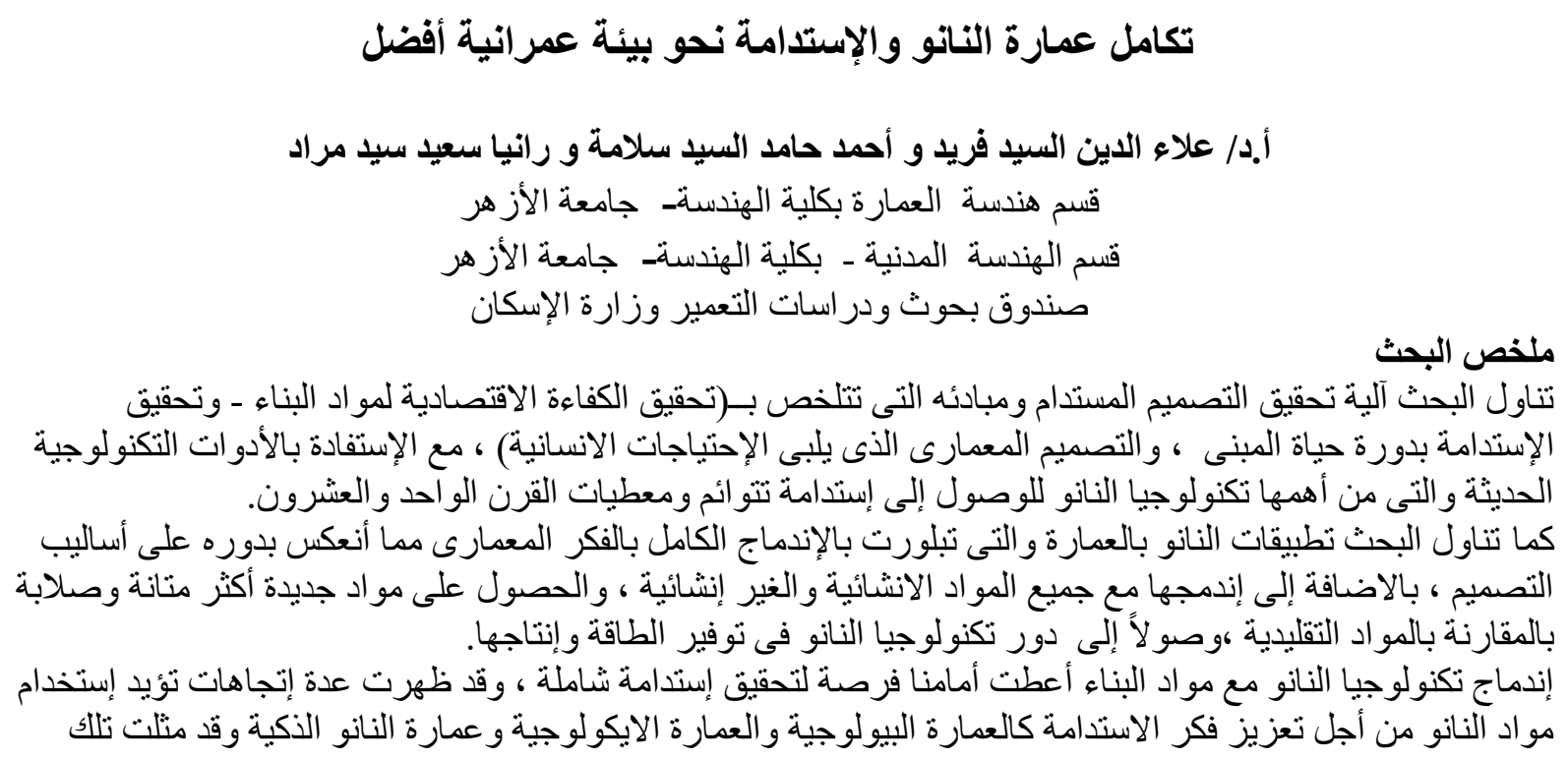


الاتجاهات التناغم التام بين التصميم المستدام وتقنية النانو بما يبشر بآفاق و اعدة فى المستقبل لصناعة البناء للوصول إلى

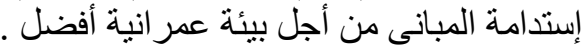
الكلمات الدالة البانة

الاستدامة ـ مصفوفة الاستدامة ـ التصميم المستدام ـ أنابيب النانو كربونـ عمارة النانو المستدامة 0

مقدمة البحث

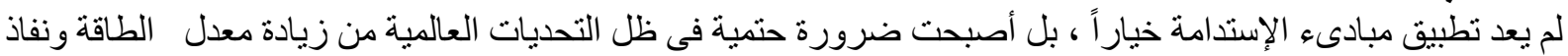

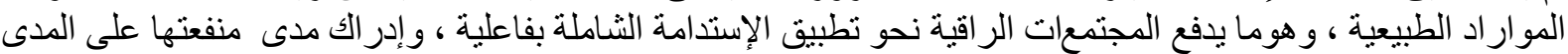

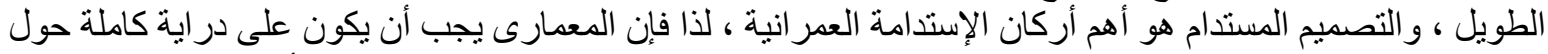

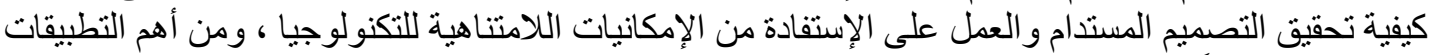

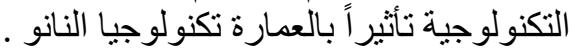

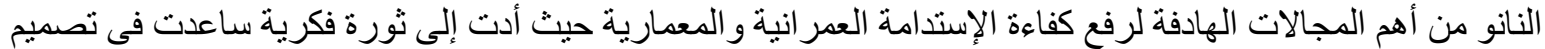

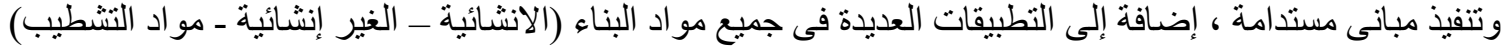

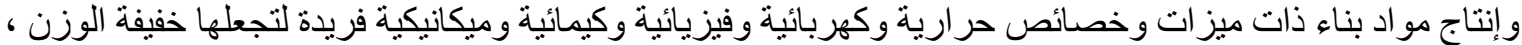

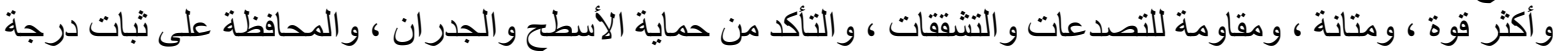

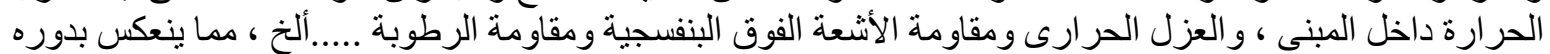

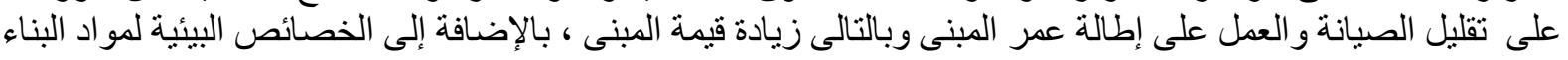

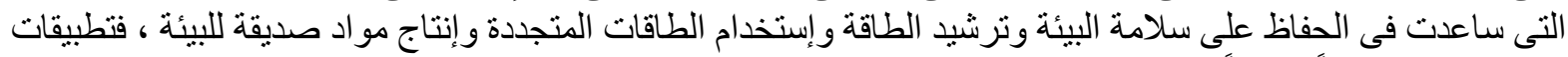

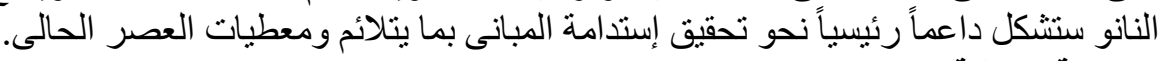
المشكلة البحثية البكائ

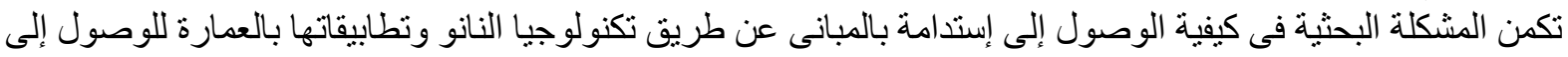

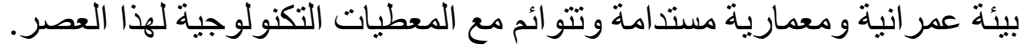
الفرضية العلمية

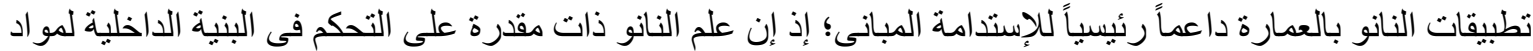

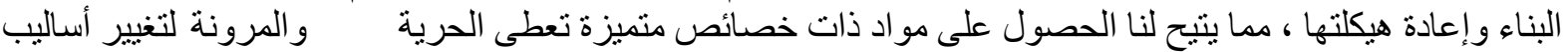
التصميج و الإبتكار المعمارى فضاء لثلا عن تحقيق عمارة نانو مستدامة.

هاف البحث البحث

يهدف البحث إلي در اسة مفهوم التصميم المستدام وتكنولوجيا النانو ، ومعرفة كيفية تحقيق الاندماج بينهما ، و إيضاح

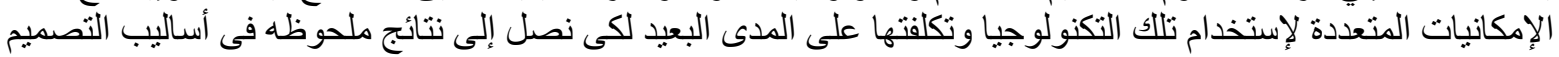

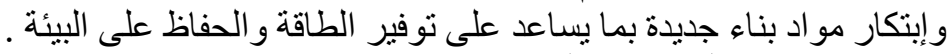

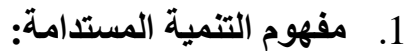

إدارة وحماية المو ارد الطبيعية ونوجيه التغير التقنى و المؤسسى بطريقة تضمن تحقيق و إستمر ار إرضاء الحاجات الئية البشرية

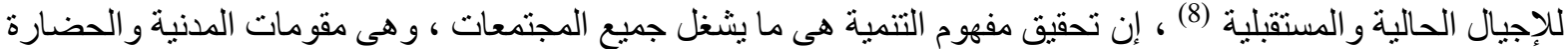

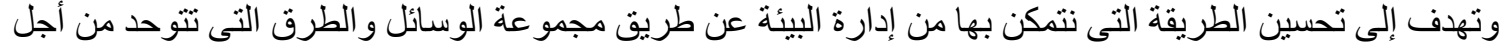

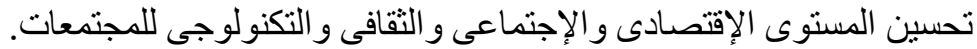

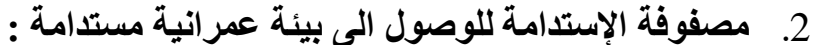

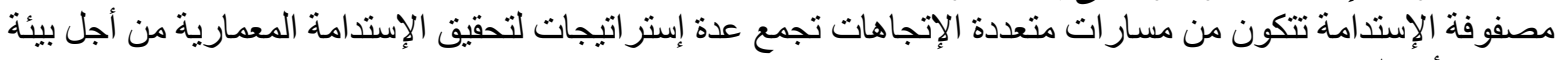
عمر انية أفضل.

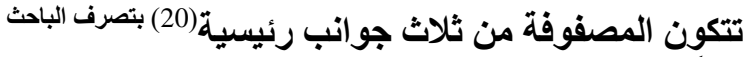

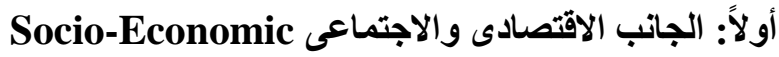

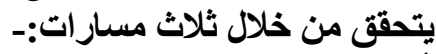

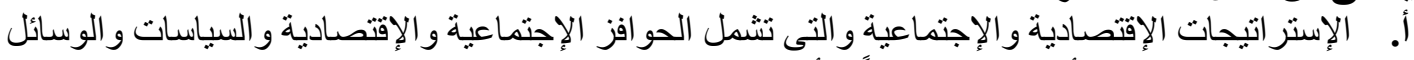

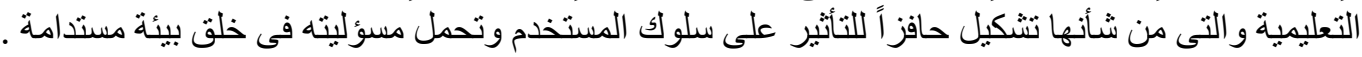

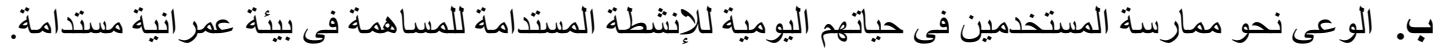

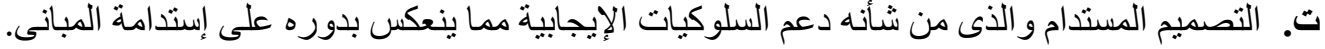

Architectural Design تثانياً: الجانب التصميمي

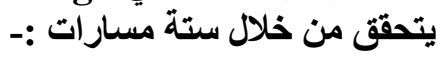


أ. ت تعزيز القيمة الإيكولوجية للمبنى كإندماج البيئة المبنية مع البيئة الطبيعية وغير ها من القيم الإيكولوجية و التى من

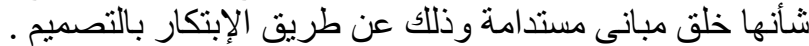

ب. التصميم الذى يتلائم مع جميع الإحتياجات السيكولوجية و الفسيولوجية ويعتبر هذا المسار هاماً لتحقيق إستدامة المبانى. (البان. ت. الإبتكار بالتصميم المعمارى و الذى من شأنه العمل على تحقيق التتمية المستدامة بصفة عامة إنمان.

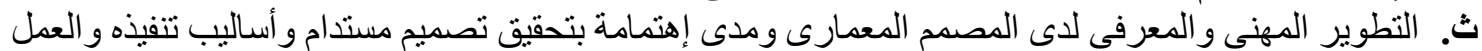

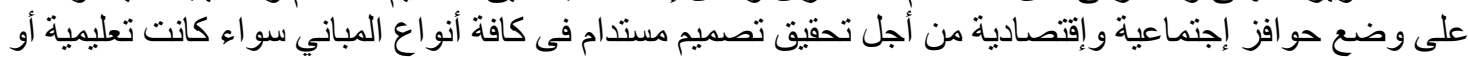

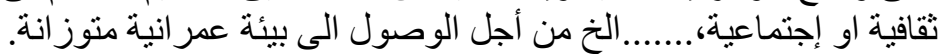

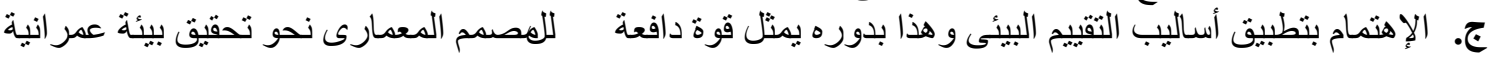

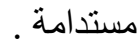
ح. الجانب التقنى ودمجه بالتصميم المعمارى ؛ إذ إن إستخدام التكنولوجيا مع وجود الاستدامة كفيلاً بتحقيق إستدامة عمر انية.

\section{Performance Environmental ثنالثاً: الجانب البيئي}

إن التصميم المعمارى المستدام هو الذى يدعم الإبنكار ويتكامل مع البيئة الطبيعية لتحقيق التنمية المستدامة بصفة عامة

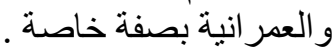

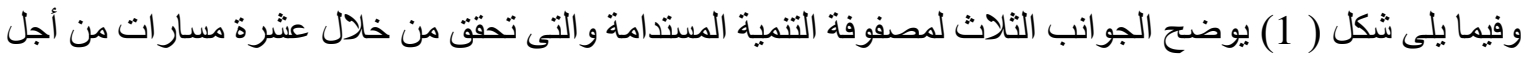
إستدامة معمارية شاملة.

3. مبادى التصميم المستدام :

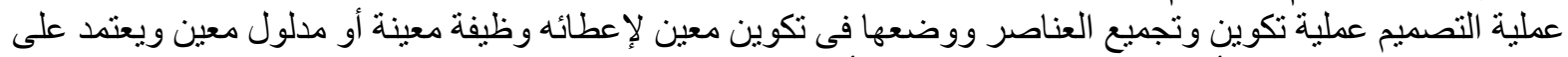

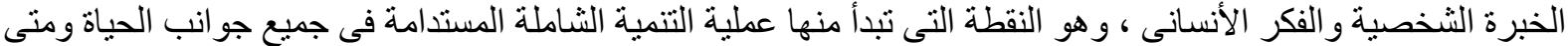
أرتبط التصميم بالإبتكار و الاستدامة كان تصميما ناجحا ـ فممارسات التصميم تتطلب تكاملاً بين الجو انب الإستر التبات التيجية

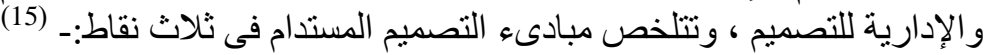
أ. تحقيق الكفاءة الإقتصادية فى الموارد المستخدمة للبناء.

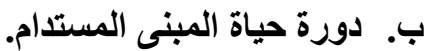
ت. تصميم يلبى الإحتياجات الانسانية.

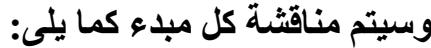

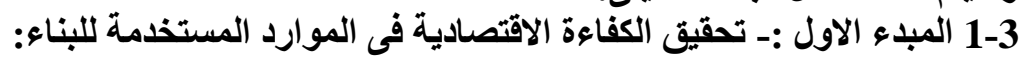

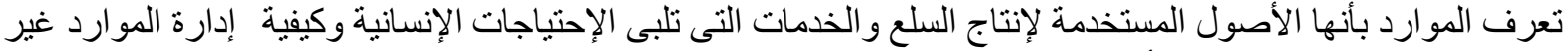

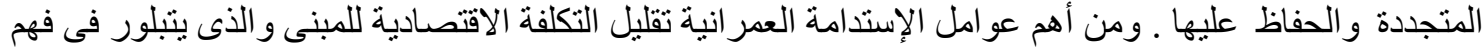

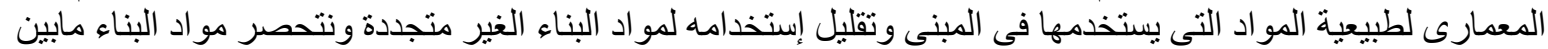

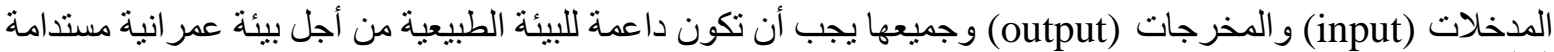

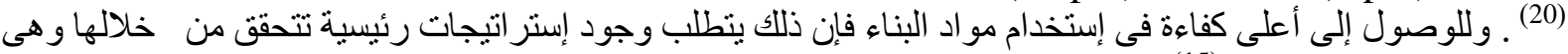
تلاث نقاط رئيسية كالتالى: الع (15)

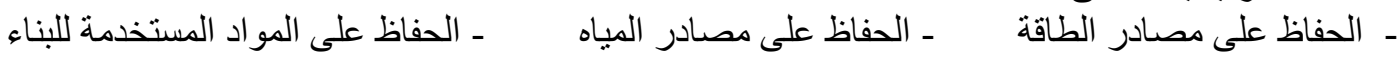




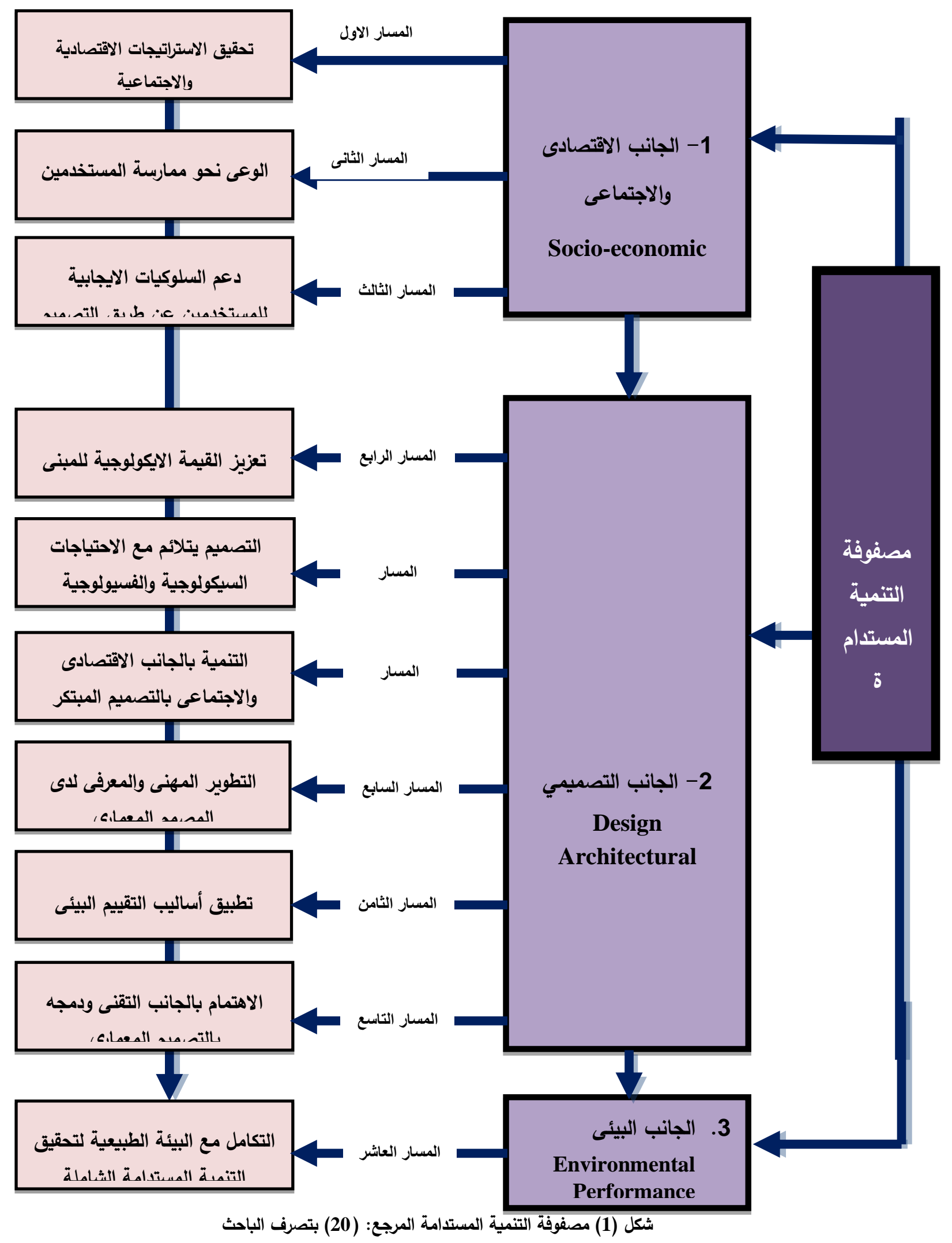




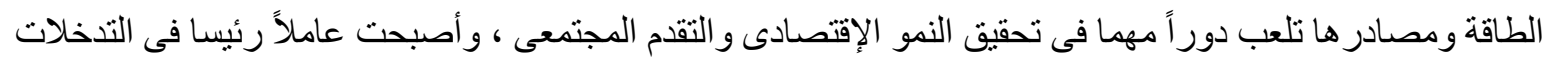

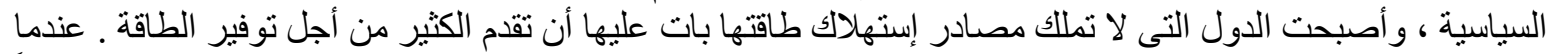

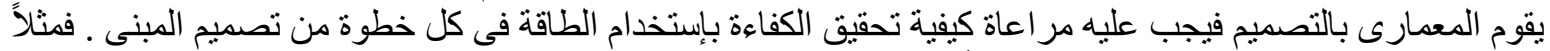

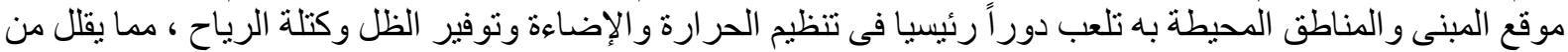

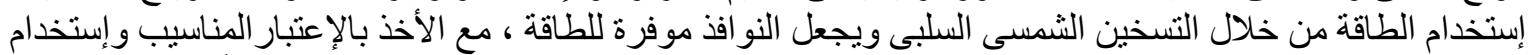

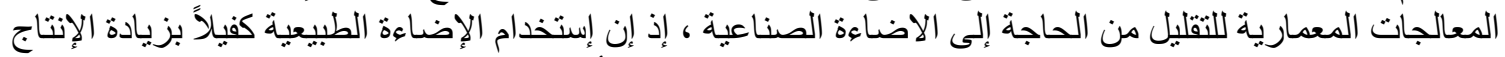

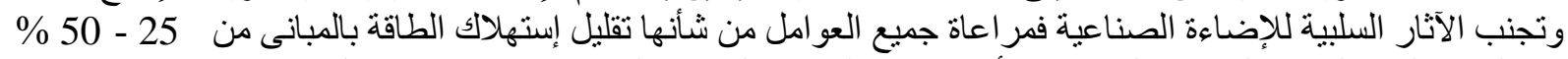

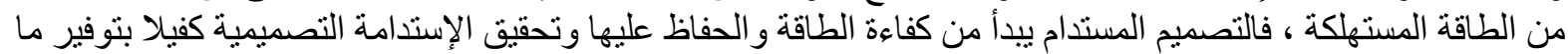

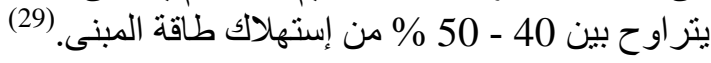

2-1-3 الحفاظ على مصادر المياه : الحد من إستهلاك وحماية المياه هي من الأهداف الرئيسية في البناء المستدام ، حيث ينبغي زيادة إعني إعماد المر افق على المياه

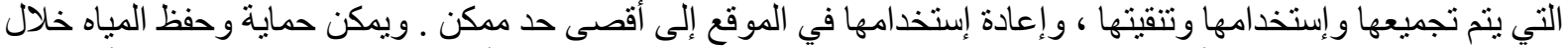
حياة مبنى من خلال تصميم أعمال السباكة المزدوجة التي تعيد تدوير المياه ويمكن أيضا تقليل مخلفات المياه إلى أدنى حد

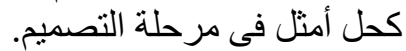

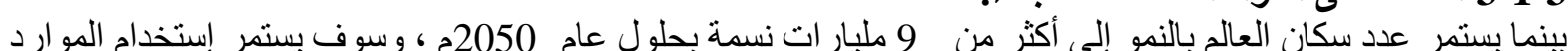

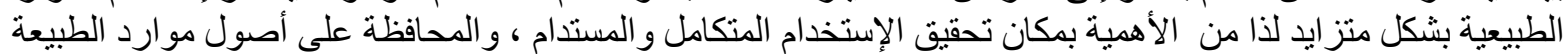

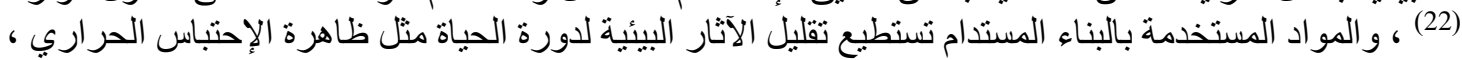

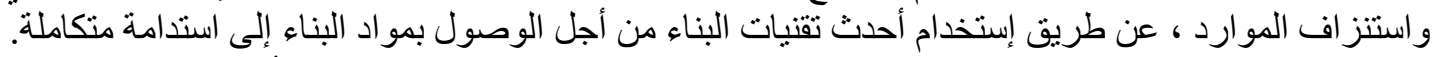

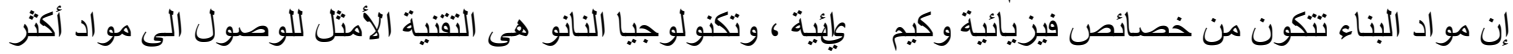

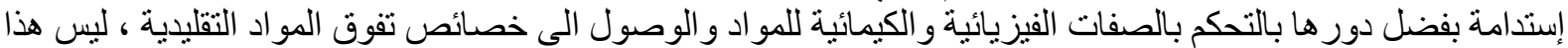

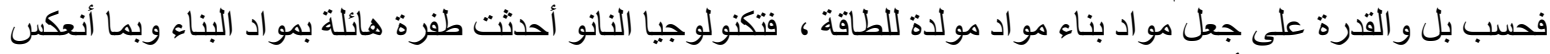

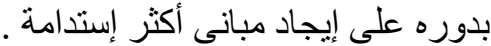
2-3 المبدء الثانى تحقيق دورة حياة المبنى المستدام :

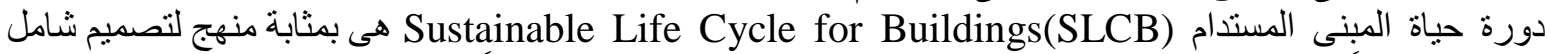

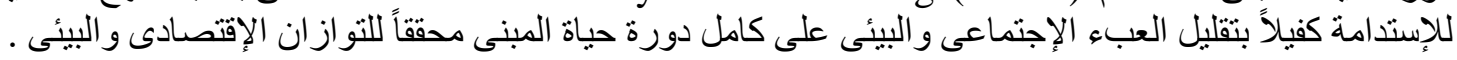

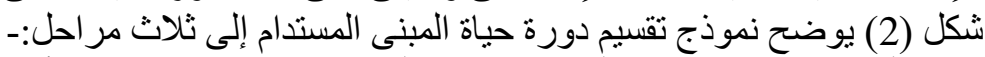

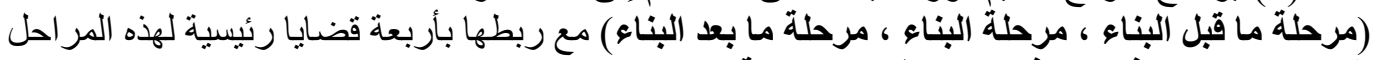

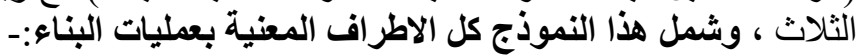

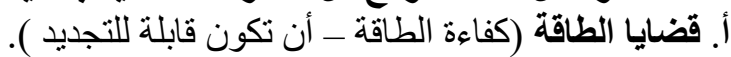

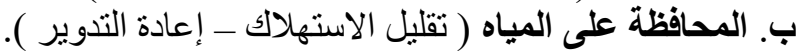
ت. مواد البناء (خفض المواء الدارد غير المتجددة - إستخدام المواد الداد المستدامة). ث. إداراة مخلفات البناء (إعادة التدوير - إعادة الإستخدام). 


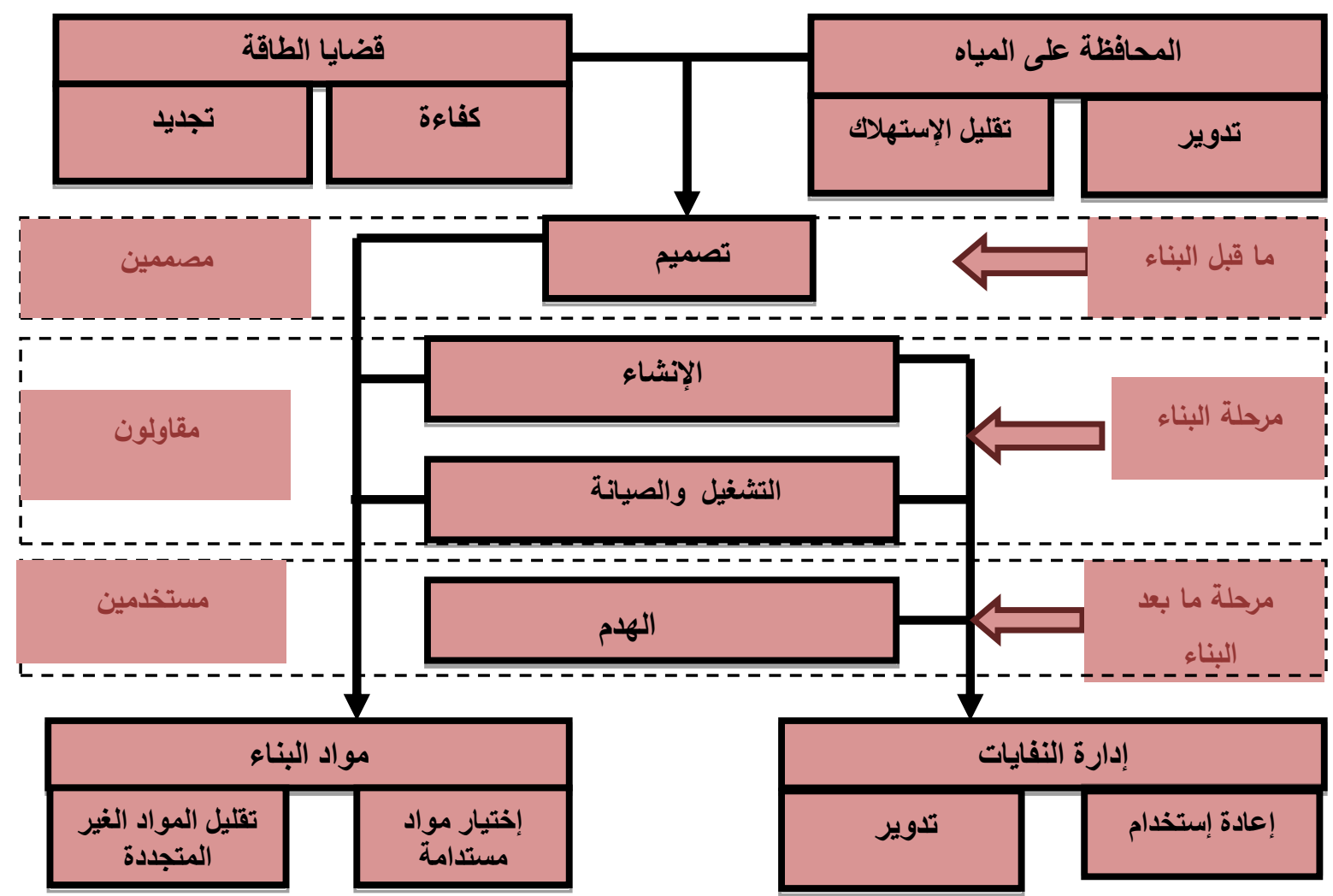

شكل (2) نموذج لاورة حياة المبنى المرجع:19 بتصرف الباحث

3-3 المبدء الثالث تصميم يلبى الإحتياجات الإنسانية:

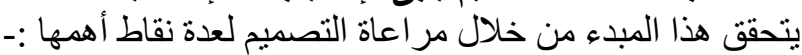

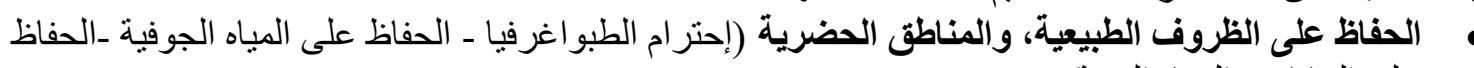
على النباتات و الحياة البرية). تصميم وتخطيط الموقع بمنهجية إستدامة شاملة (قرب الموقع من وسائل النقل - ممر ات المشاه بالموقع العام-

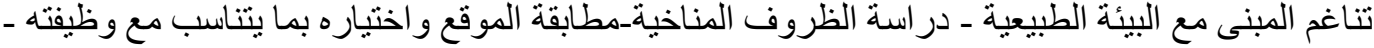

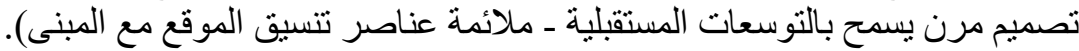

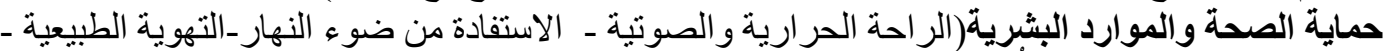
المبنى مناسب للوظيفة التى أُنشا من اجلها).

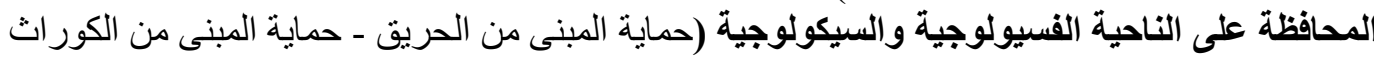

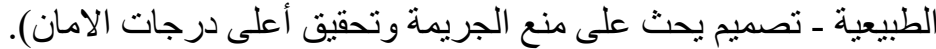

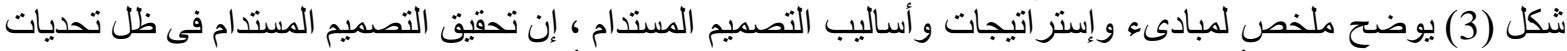

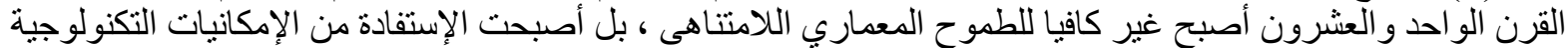

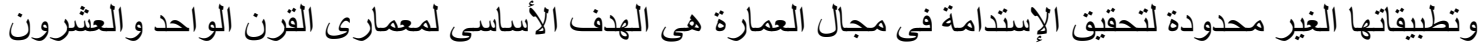

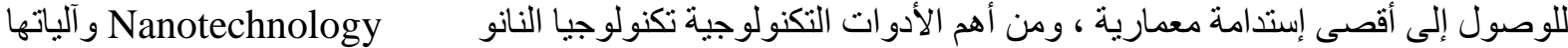
وتطبيقاتها فى مجال العمارة ، إذ إن معطيات تكنولوجيا النّان النانو من شأنها تقديم حلول مبتكرة من أجل دعم الأستدامة للوصول إلى بيئة عمر انبة مستدامة. 4- تكنولوجيا النانو: الجيل الخامس للتطور التكنولوجى (النيانو: النانوتكنولوجى) ، و الذى أصبح يحظى بإهتمام العديد من دول العالم المتقدمة و النامية

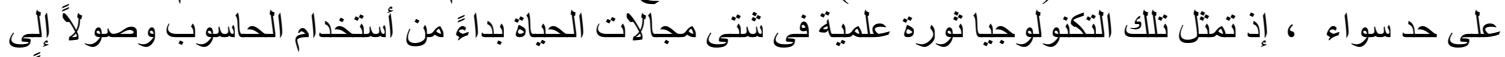

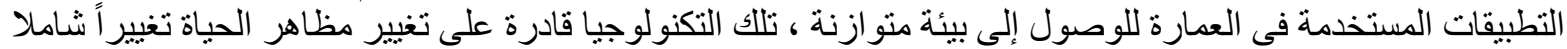
ليس هذا فحسب بل تغيير معايير القوى الموجودة ، فكل الدول تتسابق لإمتلاكها تللك التكنولوجيا للتقدم فى شتى المجالات

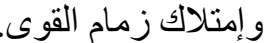
كلمة نانو : مصطلح مشتق من اللغة اليونانية القديمة (Nanos) وتعنى قصير القامة "قزم" ، و هذا يشير إلى المو اد بحجم 
النانو فى النظام المترى ، ويستخدم النانو فى وحدات علمية للالالة على و احد من المليار لذا فعند مناقشة مصطلح النانو فذللك يعنى مناقتة الاحجام - مثلاً ذرة الهيدروجين وحجمها بالقدم و المتر و النانو منر كما يلى

(16) feet \& $2.4 \times 10^{-10}$ meters \& $0.24 \mathrm{~nm}$ وقد عرفت National Nanotechnology Initiative (NNI بالو لايات المتحدة الامريكية تكنولوجيا النانوبأنها العلم

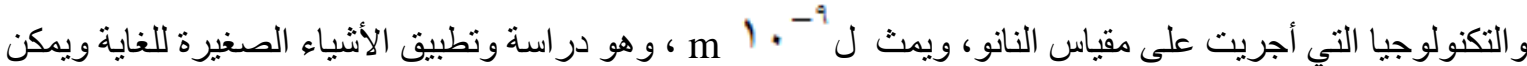

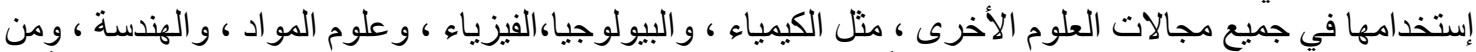

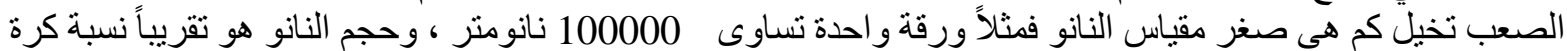

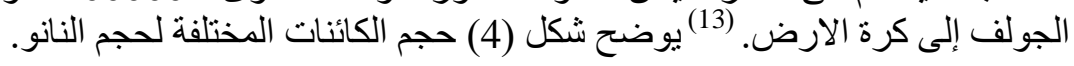

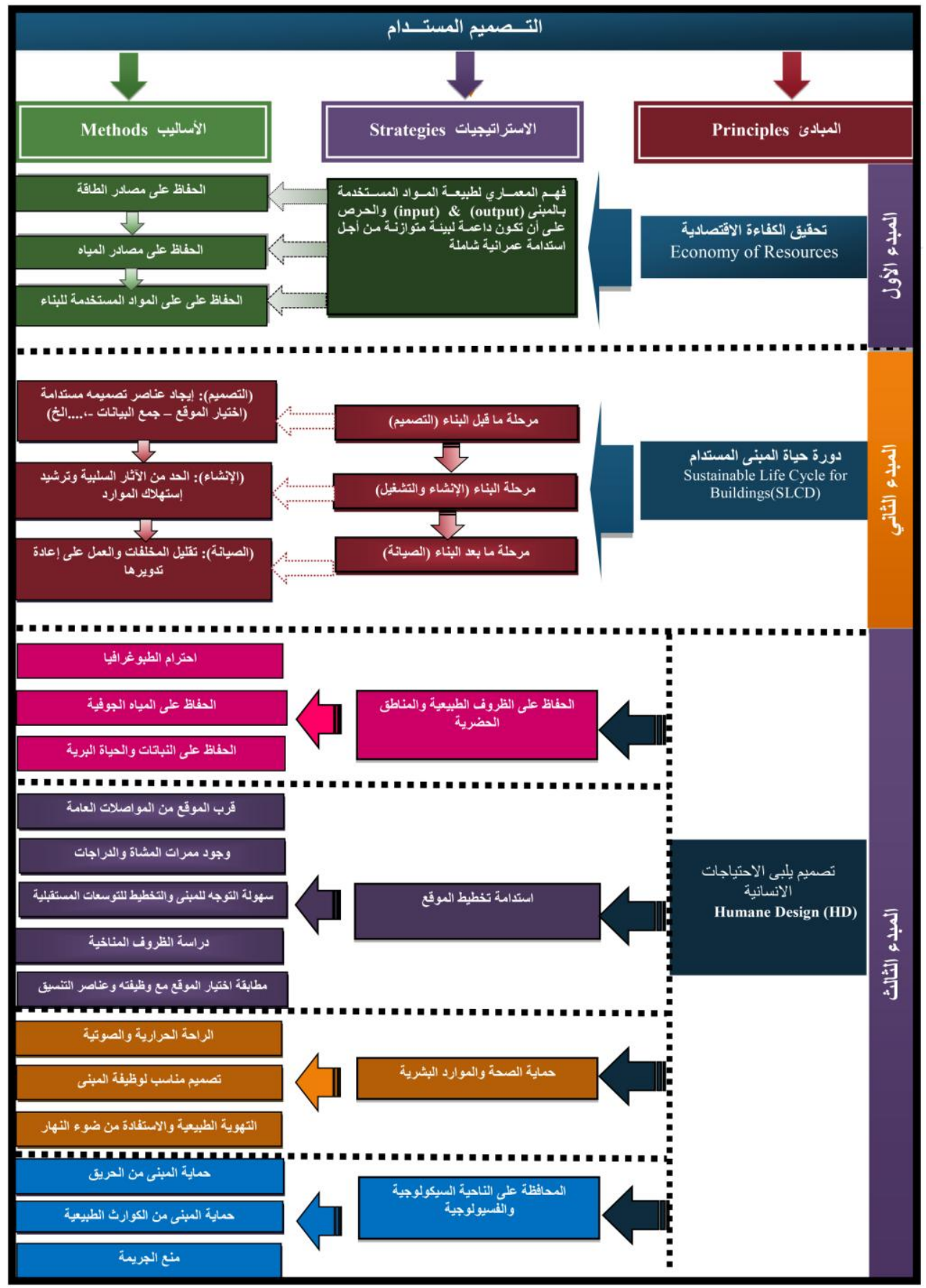


تكامل عمارة النانو و الإستدامة نحو بيئة عمر انية أفضل

The Scale of Things - Nanometers and More

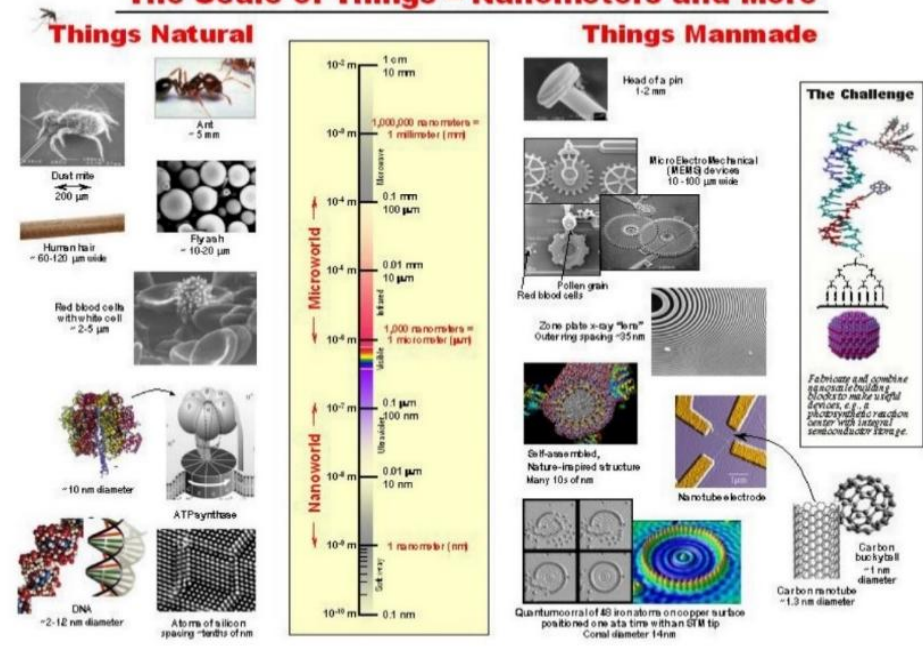

شكل (4) مقياس الكائنات المختلفة المرجع(22)

5. تطبيقات تكنولوجيا النانو للمحافظة على الاستدامة البيئة:

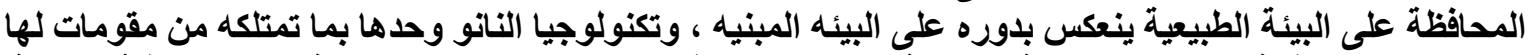

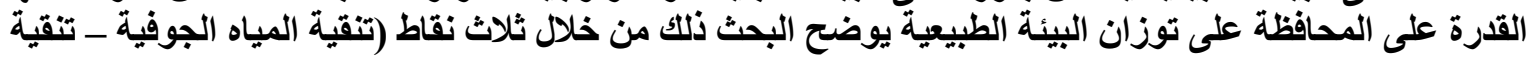
الهواء - معالجة الكوراث الطبيعية) .

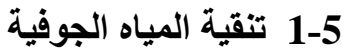
مشكلة تلوث المياه الجوفية لا تقنصة الجية على على البلدان النامية فحسب بل على العالم أجمع أن محاولة تنقية المياه بالطرق التقليدية

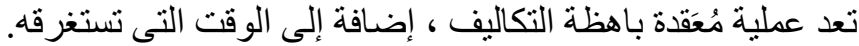

تتلخص عملية التنقية في ضانظة مكون من مسحوق حبيييات الحديد نانوية الأقطار يتم خلطها بحبيبات مسامية من الرمال

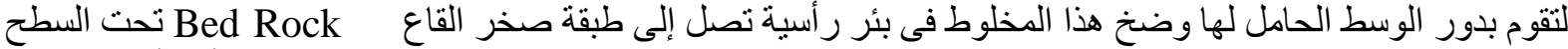

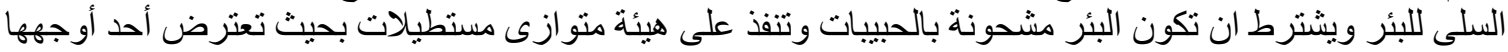

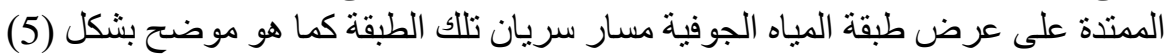

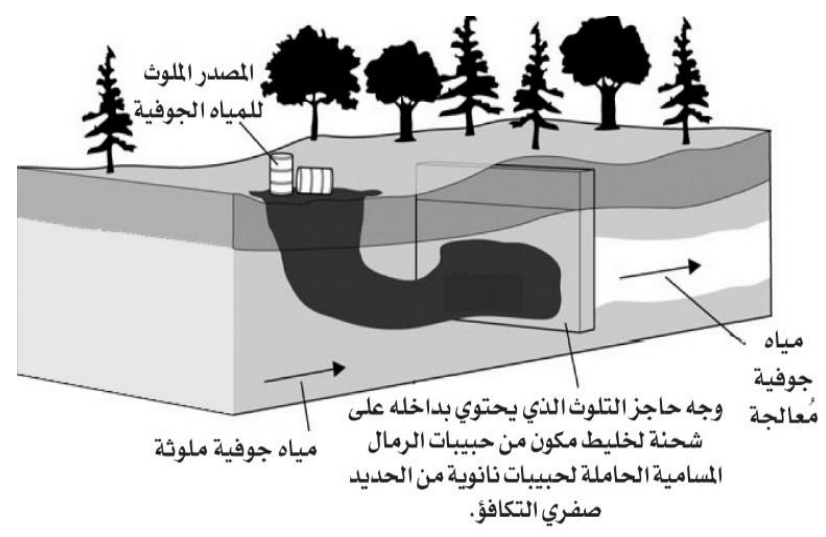

شكل (5) آلية تنقية المياه الجوية عن طريق تكنولوجيا النانو المرجع (7)

2-5 تنقية الهواء

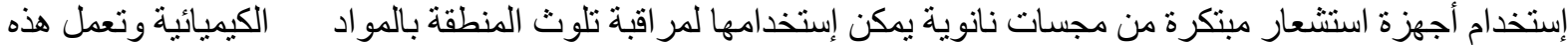

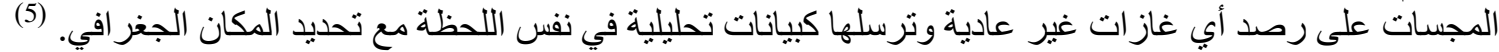

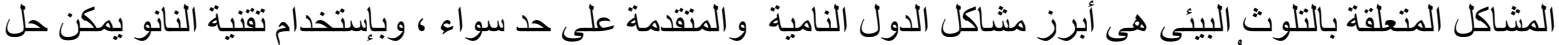

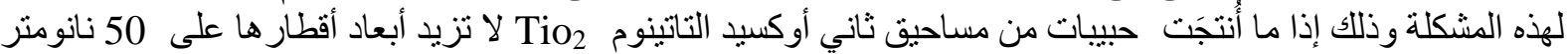




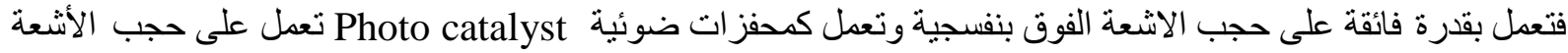

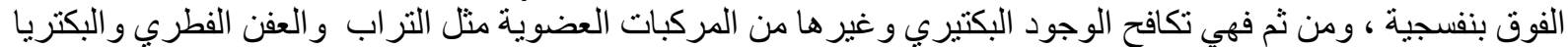
، وتستخدم للتخلص من أكاسيد النيتروجين السامة NOx و وإز التها من الهو اء الجوي، وذئل الته عن طريق تكسير ها و إختز الها

إلى مركبات صديقة للبئية. (7) البنان مما سبق فإن تكنولوجيا النانو لها القدرة على حل مشكلة التلوث البيئى و التخلص من الغاز ات السامة بالهو اء كخطوة نحو إستدامة البيئة الطبيعة وحمايتها ، و هو ما بنعكس إيجاباً على البيئة المبنية.

3-5 تطبيقات تقنية النانو معالجة الكوراث الطبيعية:

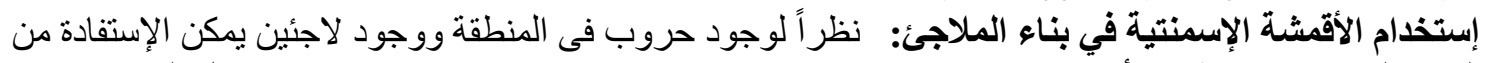

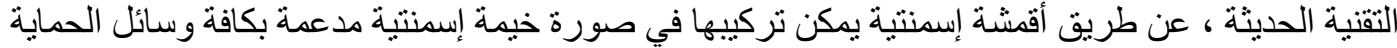

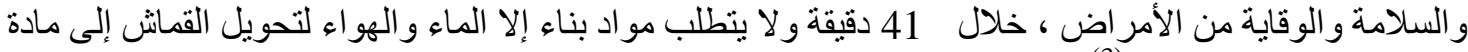
صلبة في خلال 12 ساعة.

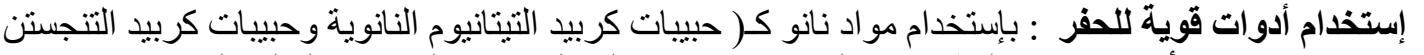

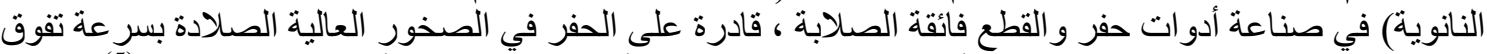

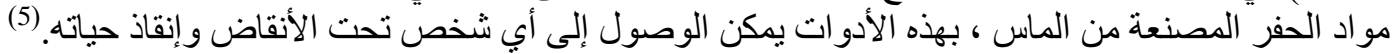

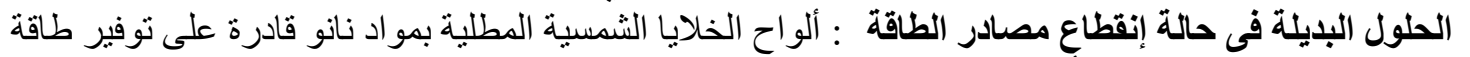

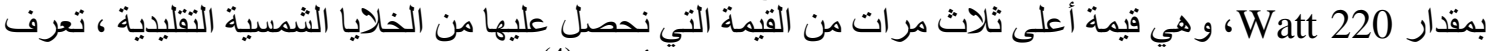

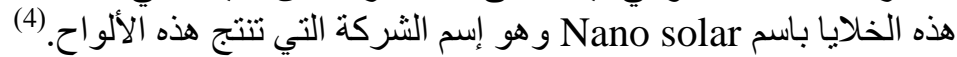

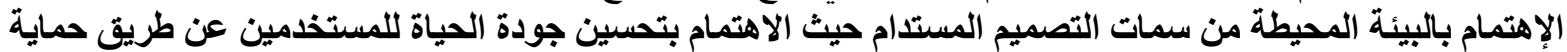

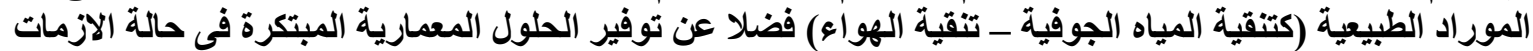

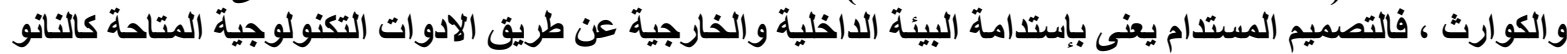

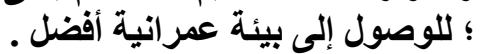
6- 6مارة النانو

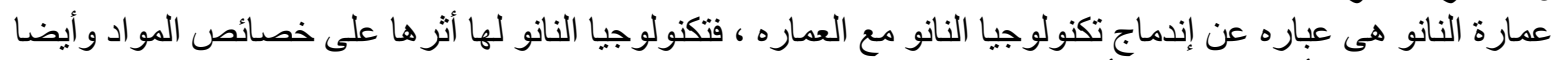

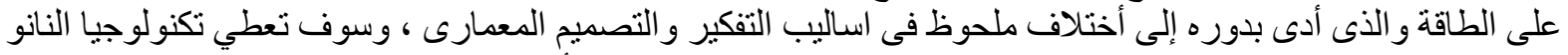
قوة غير مسبوقة للمعماريين لتشكيل عالمنا بطريقة مبتكرة ، فضلا عن علاقة أكثر إستدامة بين البيئة الطبيعية و العمر انية.

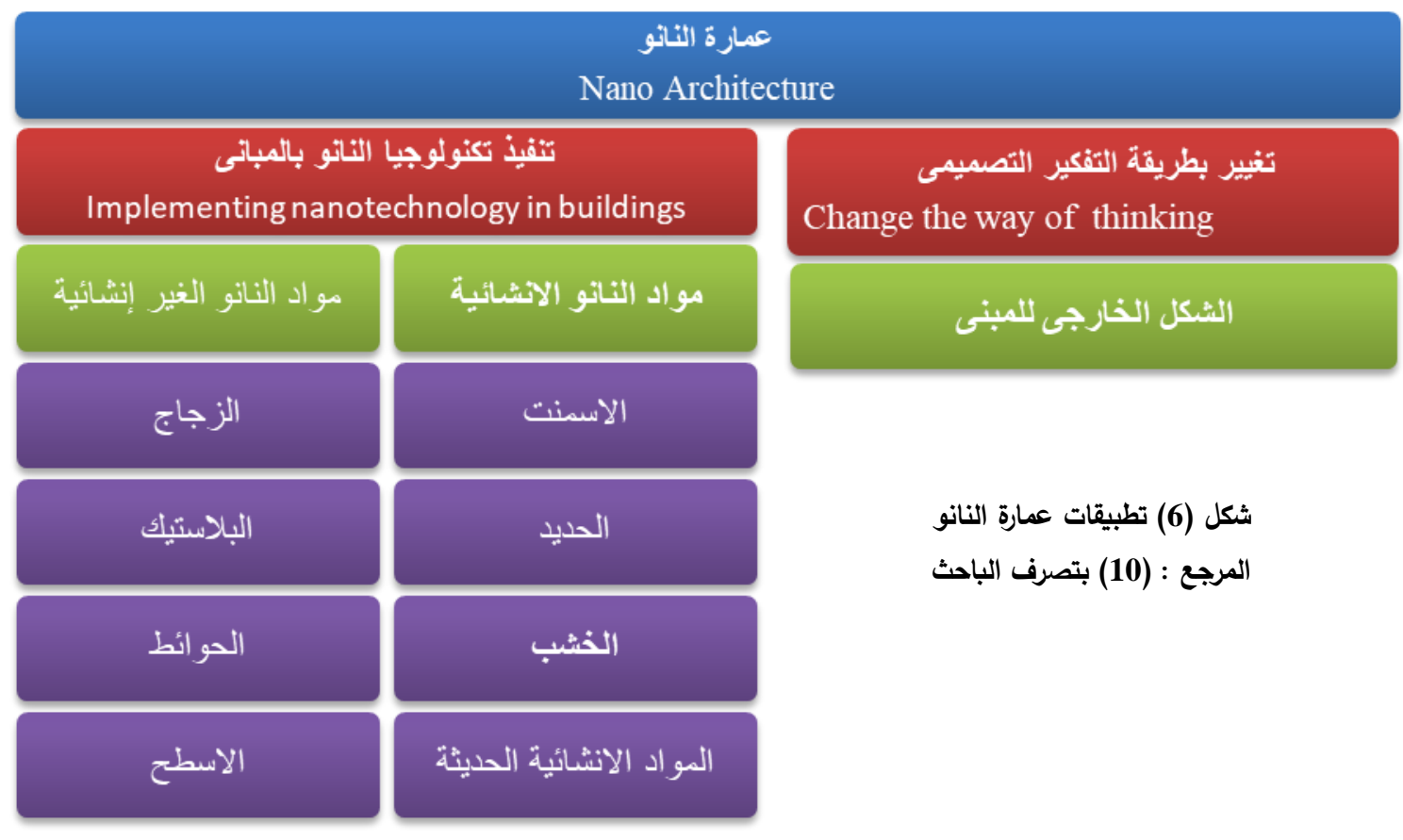

1-6 تغيير طريقة التفكير التصميمى (الثكل الخارجى للمبنى) :- 
دمج تقنية النانو بالعمارة أدى إلى ظهور أنشكال معمارية جديدة New Architectural Form كان من الصعب تتفيذها ،

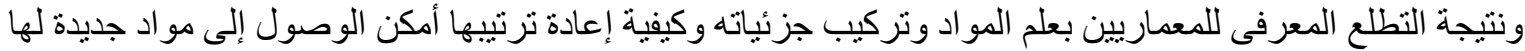

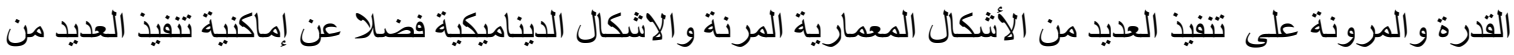

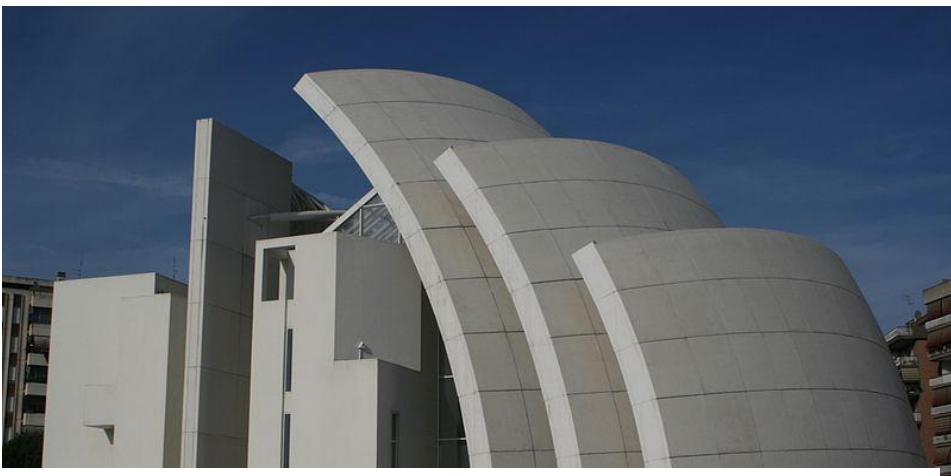

شكل (7) مبنى Jubilee Church والاندماج مع تطبيقات النانو 27: المرجع

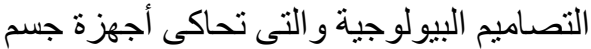

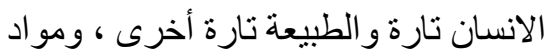
البناء كانت العامل الرئيسى فى تغبير شكل ووظيفة المبنى. شكل(7) يوضح مبنى الى وكيفية تطويع المو اد التقليدية كالخرسانة لتنفيذ الثكل الخارجى للمبنى و الذى يتميز بالمرونة

شكل المبنى مستوحى من فكرة الثالوث

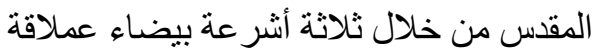
ارتفاعها 27م ، و الكنيسة و اقعة في منطقة عالية التلوث بعو ادم السيار ات ودخان

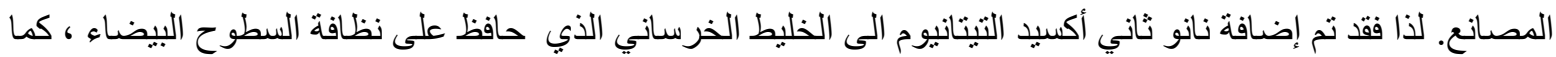

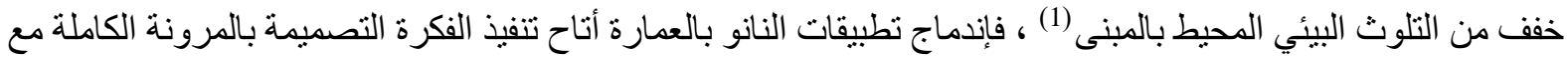
المحافظة على إستدامة المبنى وحمايته من التلوث.

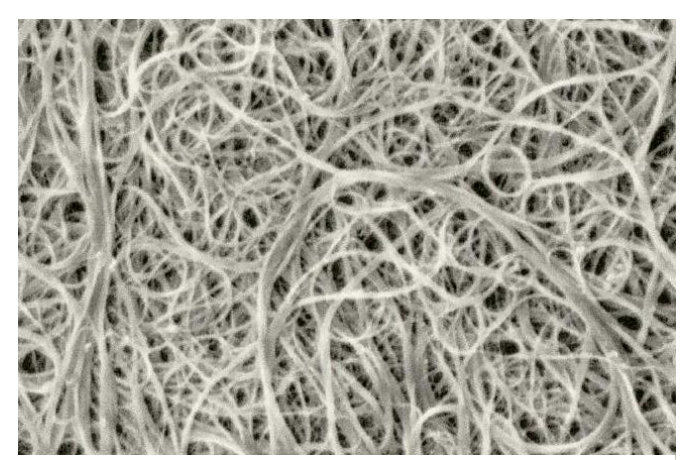

شكل (8) صورة مجهرية باستخدام مجهر المسح

النفقي لحزم الأنابيب النانوية الكربونية

2-6 تنفيذ تكنولوجيا النانو بالمبانى (المواد الإنشائية الحديثة)

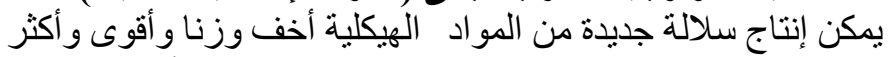

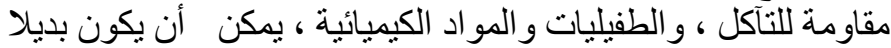

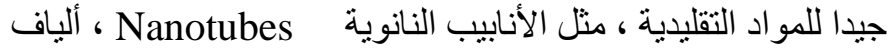
Nano sheets of ونانوشيتس من الكربون Nanofibers النانية

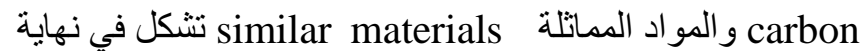
المطاف الهياكل العظمية الهيكلية للمباني الجديدة.

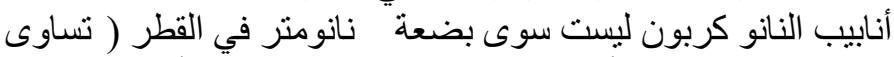

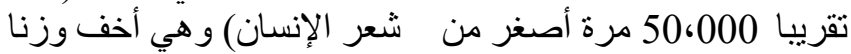

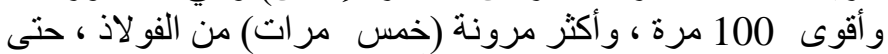

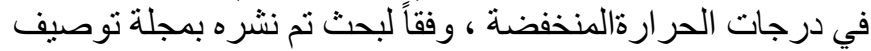

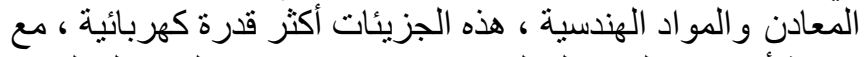

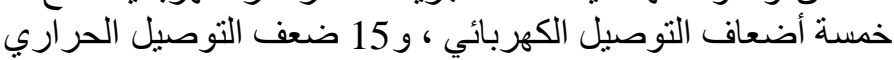

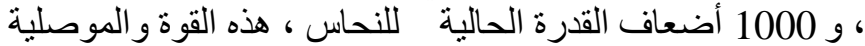

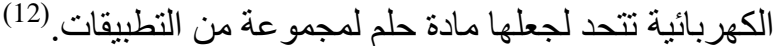

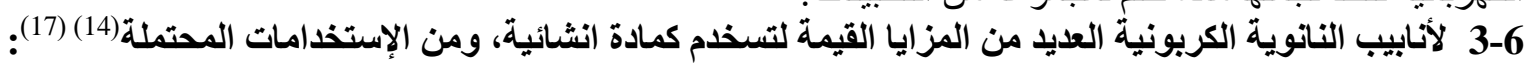

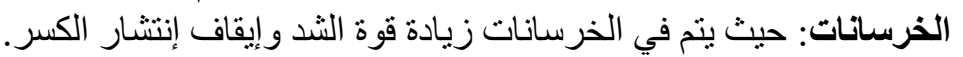

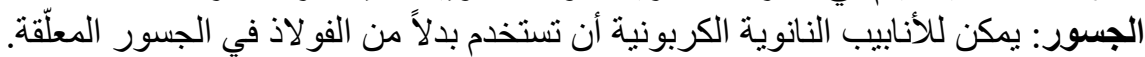

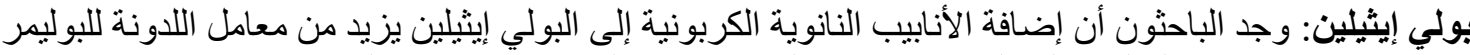

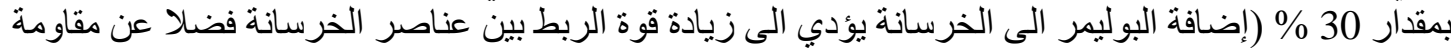
التجمد وزيادة مقاومة الانحناء للخرسانة البن......الخ).

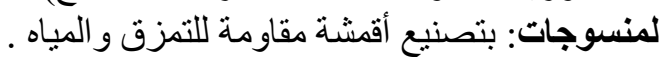

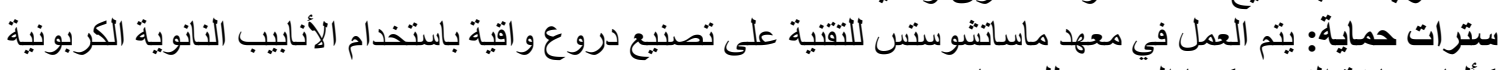

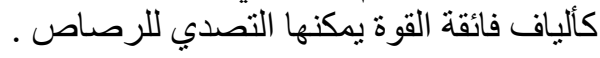

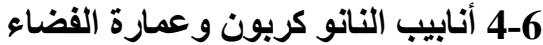
00062 ميل في الفضاء من أجل إطلاق السواتل(الساتل هو جهاز تتمثل الفكرة في إرسال كابل يبلغ طوله 


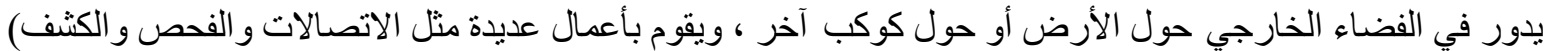

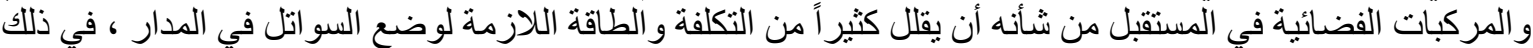

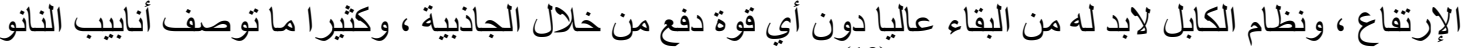

الكربونية باعنبار ها الحل الأمثل لتحقيق ذلك. لالكان (13)

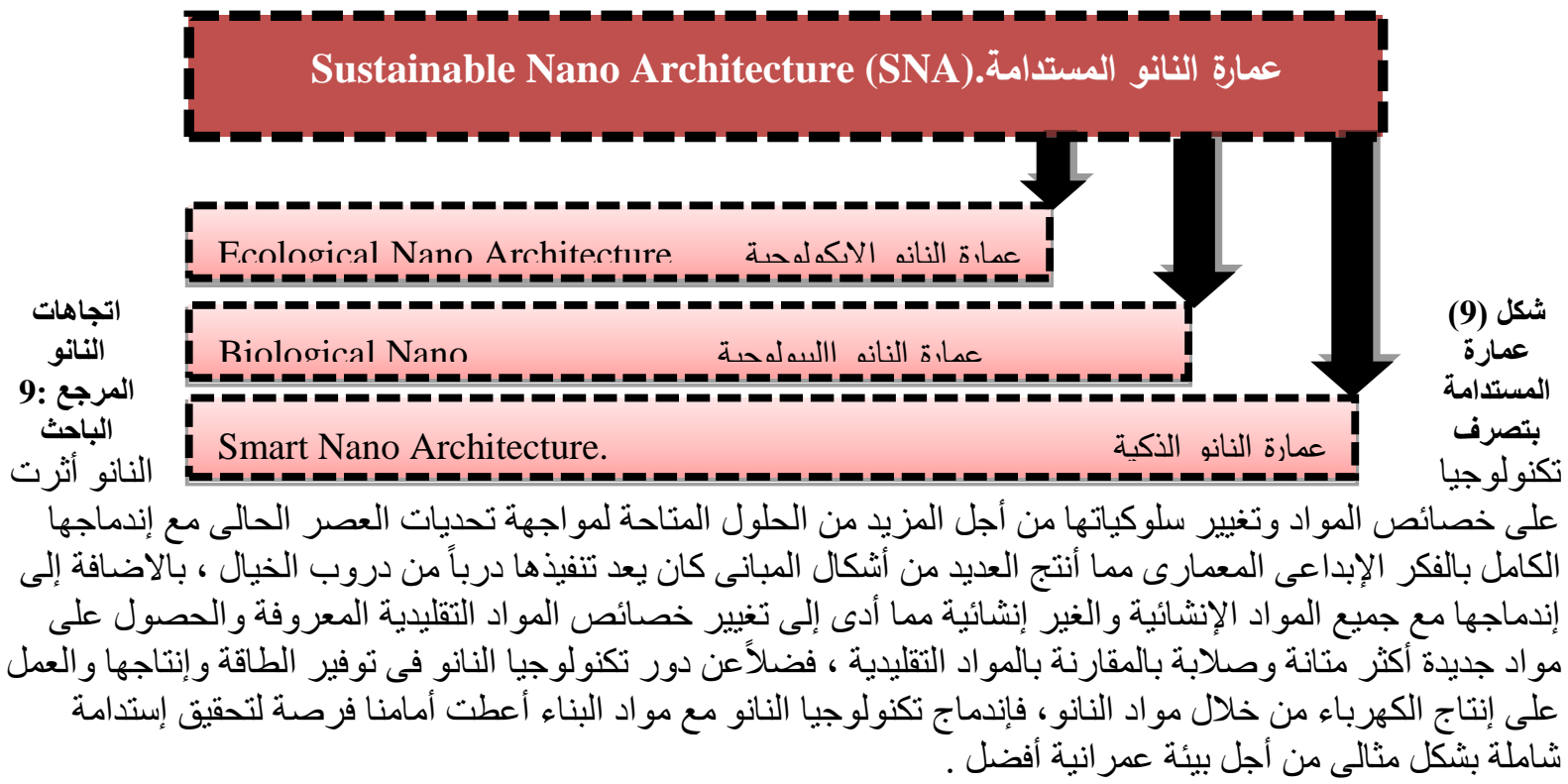

7.

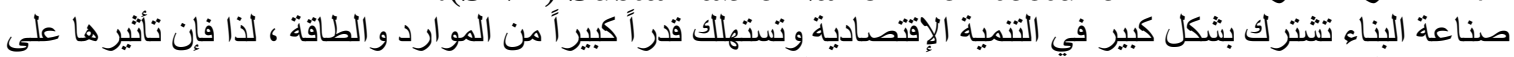

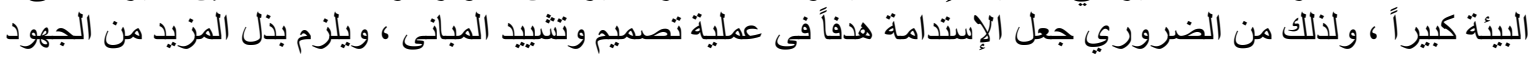

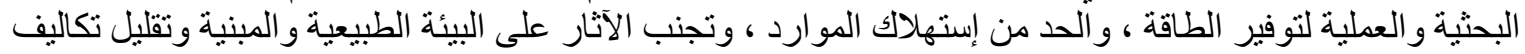

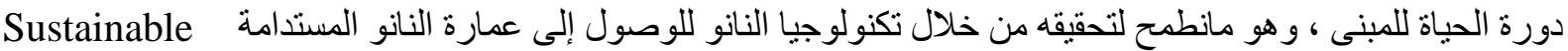
Nano Architecture (SNA).

من أهم الإتجاهات المويدة لعمارة النانو المستدامة عمارة النانو البيولوجية Biological Nano Architecture نوضح

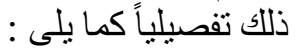

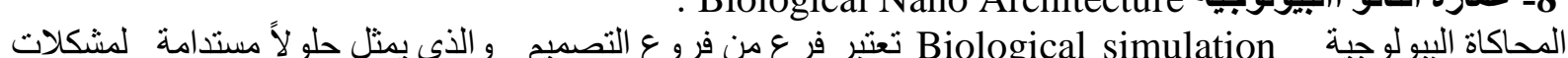

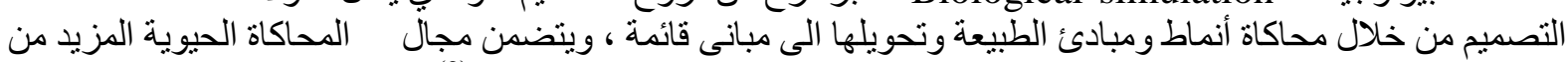

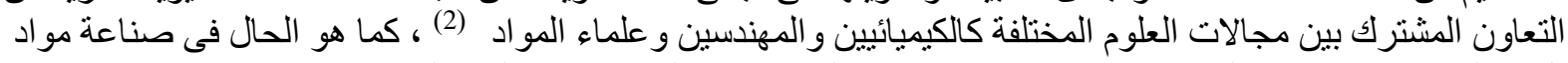

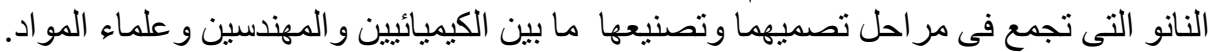

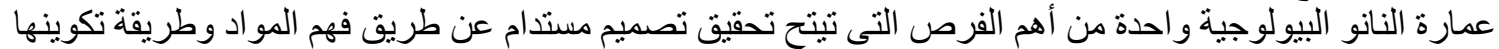

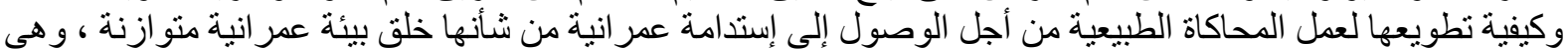

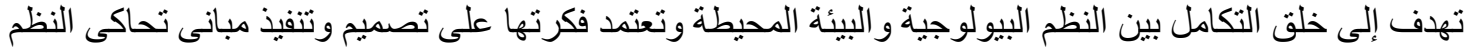

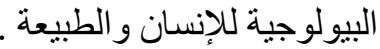

إن تحقيق الاندماج الكامل بين التكنولوجيا الحيوية وتكنولوجيا لونيا النانو يقودنا حتماً إلى نتائج عملية يمكن للمعماريين بها

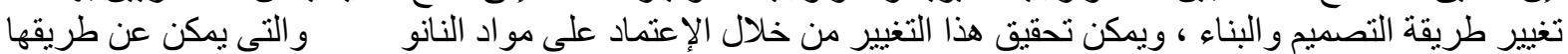

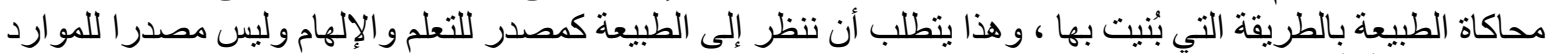

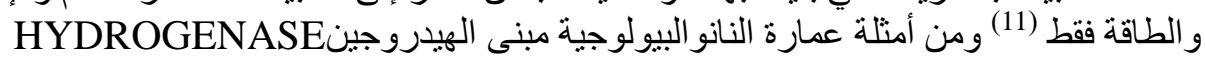


9- مبنى الهيدروجين HYDROGENASE

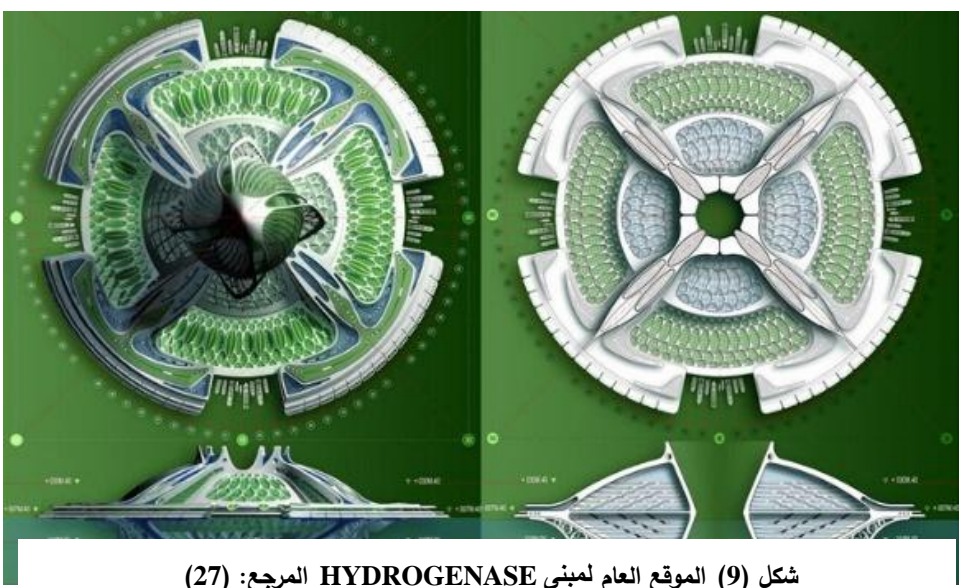

شكل (9) الموقع العام لمبنى HYDROGENASE المرجع: (27)

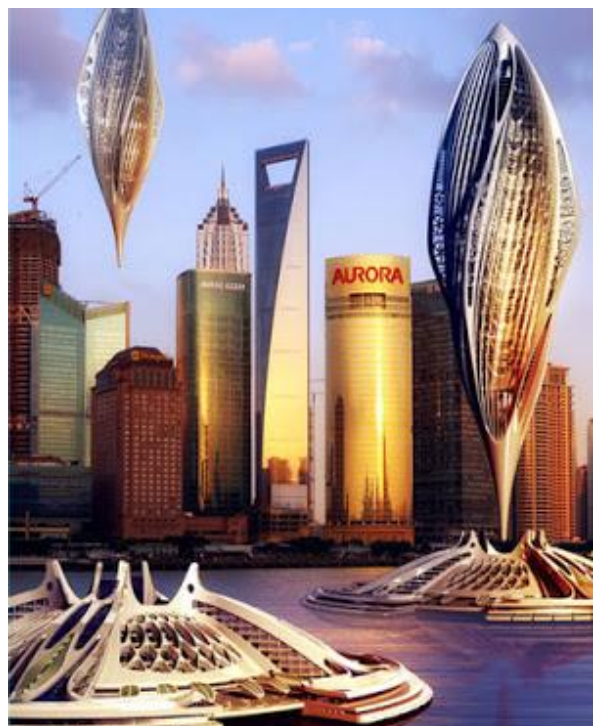

شكل (10) مبنى HYDROGENASE المرجع(23)
الوظيفة:سكنى ترفيهى - مزر العين للطحاب الشحن الجوى - منطاد من الهيدروجين. الموقع : الصبن ، شنغهاى، بحر الصين الصنين

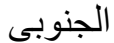

الثحن : الشرعة : 200 طن السرعة : الثرع : 175 كم/الساعة طن

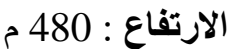

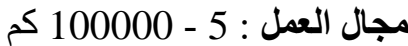
القطر : 180 م :

المساحة السطية : 350.000 م 2

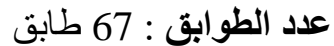

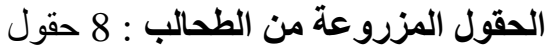

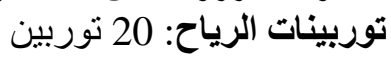
معامل استخراج الهيدروجين : 32 معدرين

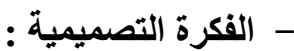

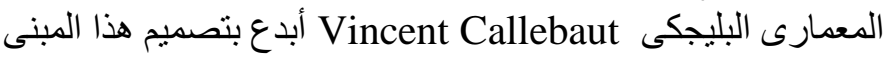
و الذى يعد من المبانى العائمة وقد تخيل المعمارى. Vincent Callebaut الركاب ، ولكن أيضا كمباني عائمة متعددة الإستخدامات (ترفيهية ،

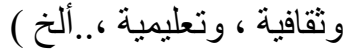
المبنى سيحدث نقلة نو عية في تصميم المطار ات و وإستخدامها

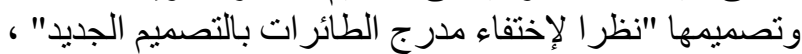

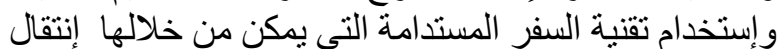
المسافرين بالطاقة النظيفة ودون أدنى تأثير على البئية البئة المحيطة

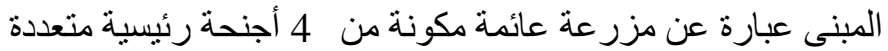

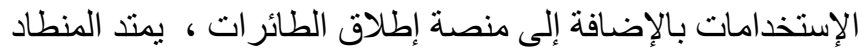

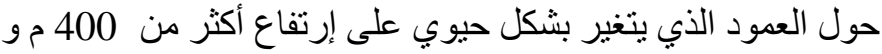
180 م من القطر ، مشكلا زهرة كبيرة على على الفي إنى إستعداد للفتح.

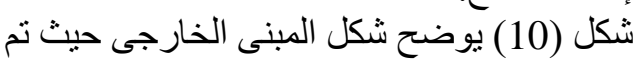
تقسيم المساحات إلى 4 قطاعات مأهولة باتلة بالسكان بين 4 فقاعات كبيرة ضخمة مع الهيدروجين الحيوي، الذى يتيح إنتاج طاقة متجددة. هذه الفقاعات مصنو عة الفئ في سبيكة

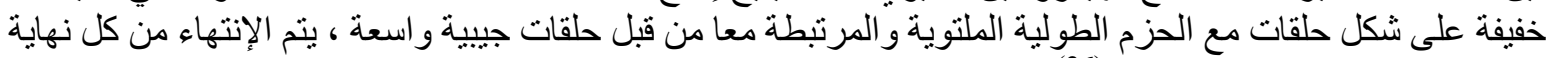

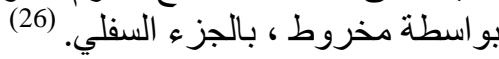

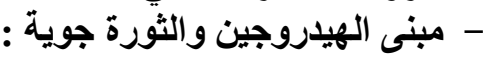

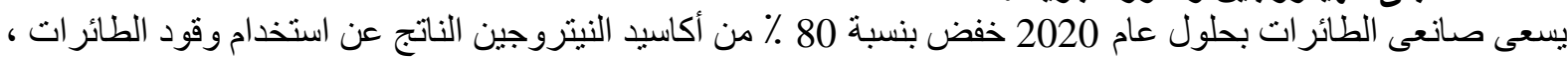

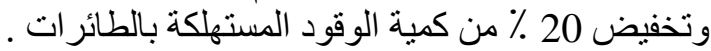

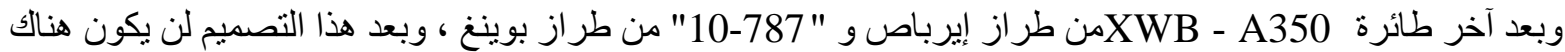

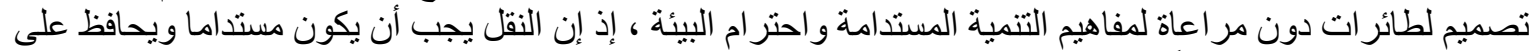

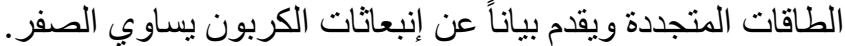

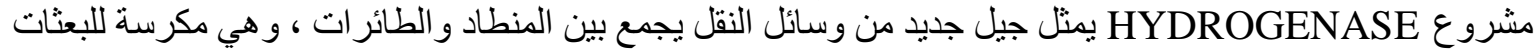

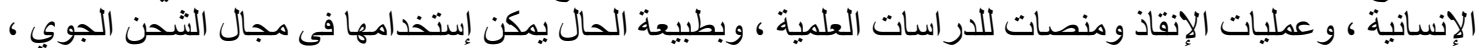

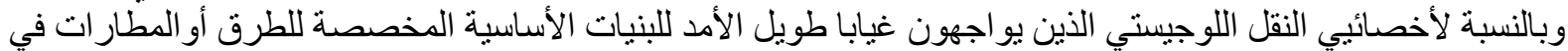

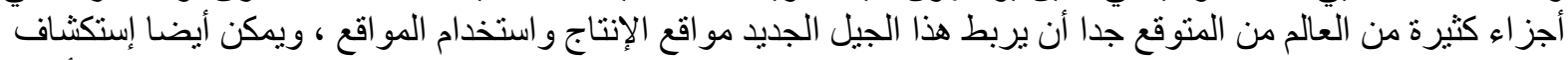

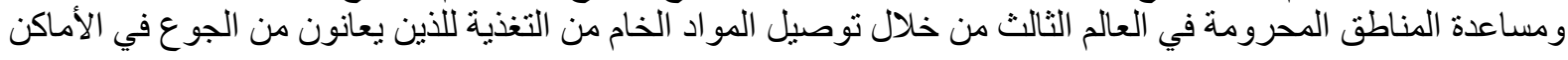


مبنى HYDROGENASE لا يقتصر دوره فقط على ما سبق بل هناك أنشطة تكميلية أخرى كالترفيه و السياحة البيئية و الفنادق ، و التغطية الإعلامية الجوية ، ومر اقبة المياه الإقليمية ، كل هذا فى إطار كامل متكامل بين الإستدامة و العمارة

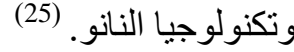

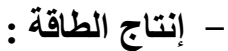

الهدف من المشروع بحلول عام 2030 يمكن أن تكون هناك مزارع في في المحيط تنتج الوقود الحيوي من الطحالب البحرية

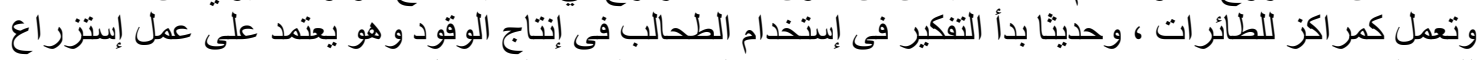

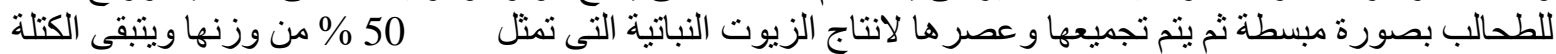

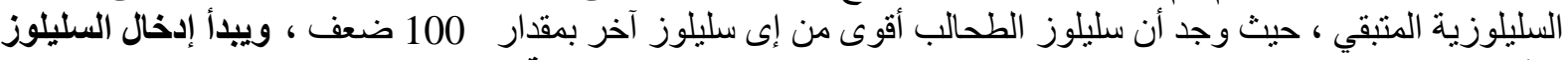

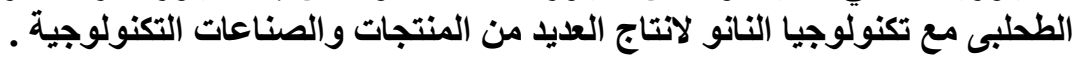

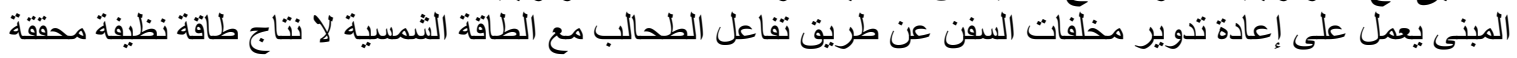

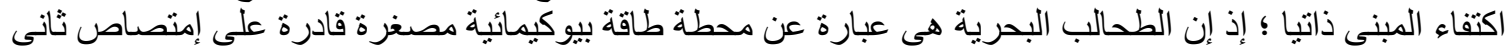

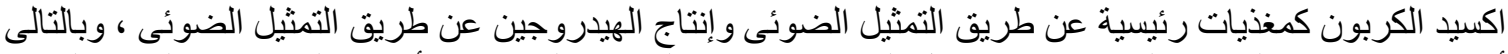
أمكن إعادة تدوير النفايات البحرية بنسبة تصل إلى 80 \% \%ن الغاز ات الكربونية و أكاسيد النتيروجين المسبية للإحتباس

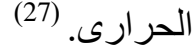

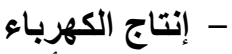

بين الهندسة وعلم الأحياء ، مبنى HYن و احداً من المشاريع الأولى التى تم بها إنتاج الكهرباء بطريقة

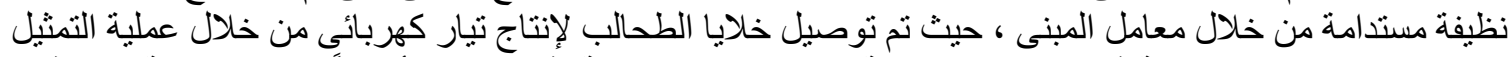

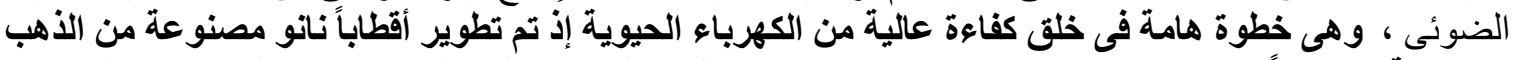

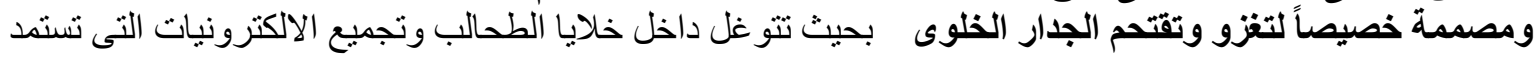

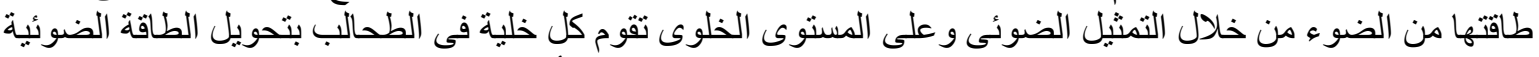

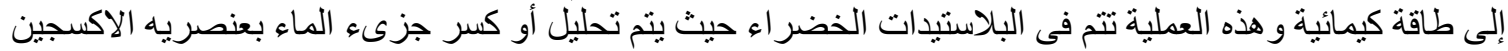

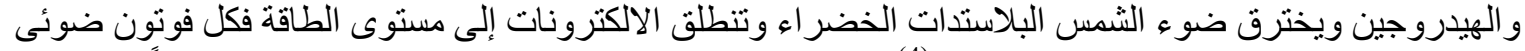

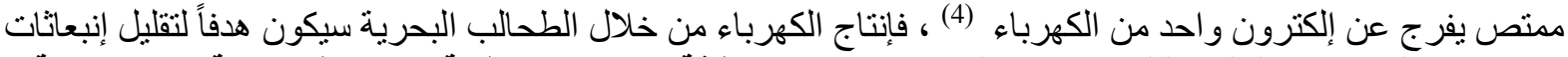
ثانى اكسيد الكربون وبالتالى تقليل الإحتباس الحرارى وإنتاج طاقة من مصادر نظيفة وهى خطوة هامة نحو إستدامة التئة

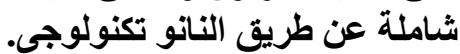
وفيما يلى شكل (11) يوضح مصنادر الطاقة وعناصر مبنى التونى 


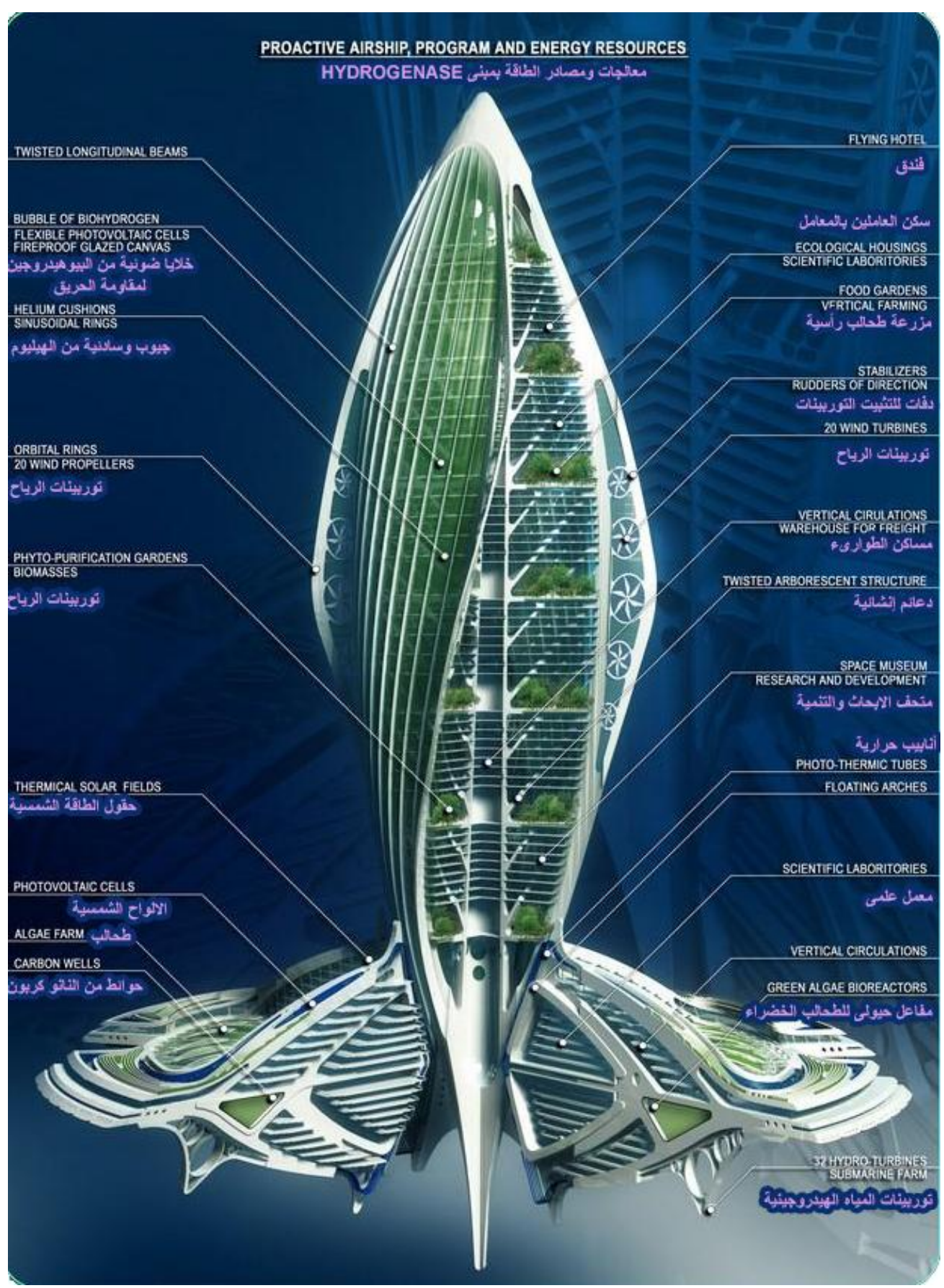

شكل (11) يوضح يوضح مصادر الطاقة وعناصر مبنى الـ HYDROGENASE المرجع: (26)

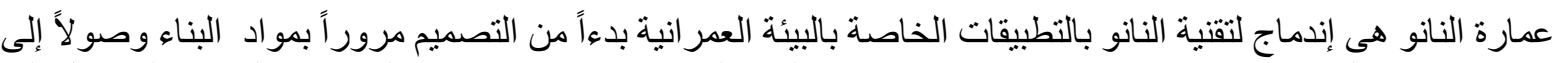

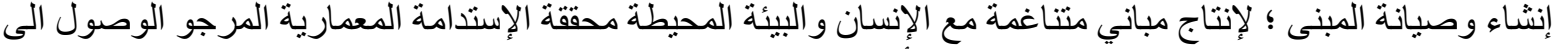

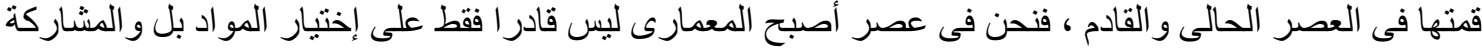

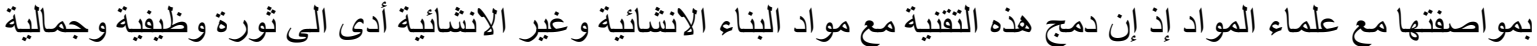

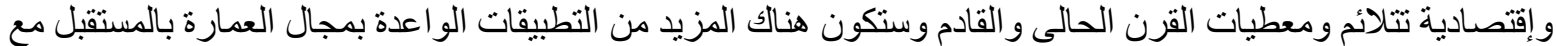

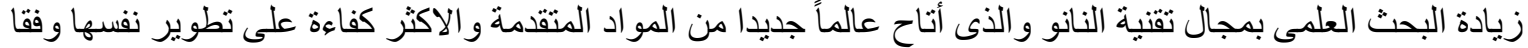

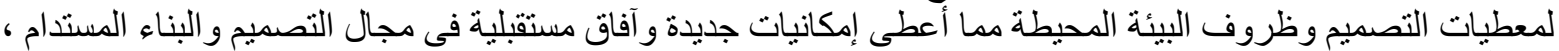
فضلاً عن ظهور العديد من الإتجاهات التى تدمج الاستدامة بالنانو وبالتالى إلى عمارة نانو مستدامة من أجل بيئة عمر انية النية 


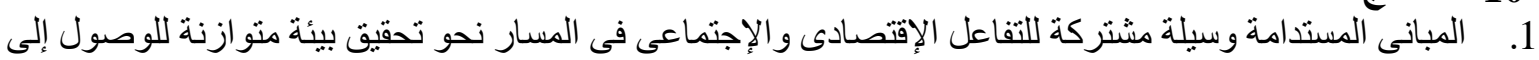

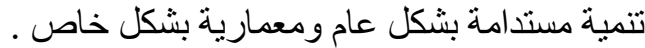

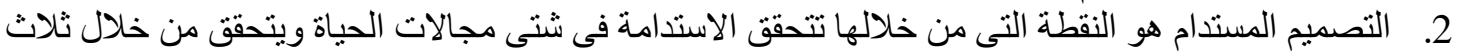

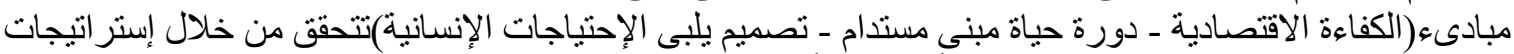

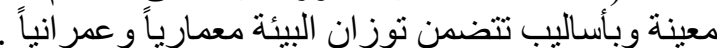

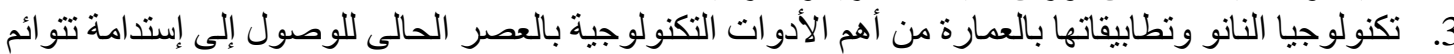

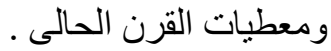

4. تطبيقات النانو بالعمارة داعماً رئيسياً للإستدامة المبانى، عن طريق مو اد البناء ، مما أتاح الحرية الكاملة لتغيير

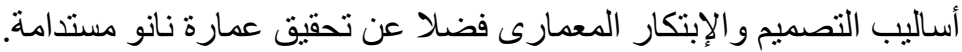

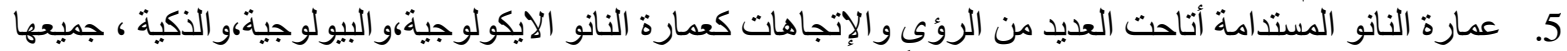

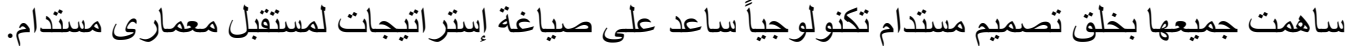
- 9

1. يوصى البحث بضرورة تشجيع الأبحاث العلمية الخاصة بتطبيقات تكنولوجيا النانو بجميع المجالات بهدف نشر ثقافة البحث العلمى .

2. إعداد وتأهيل الخبر العثى المحلية للإستفادة منها بمجال تكنولوجيا النانو مع إنشاء مختبر ات كاملة ومجهزة لخدمة الباحثين و المهتمين بتلك التكاد التكنولوجيا.

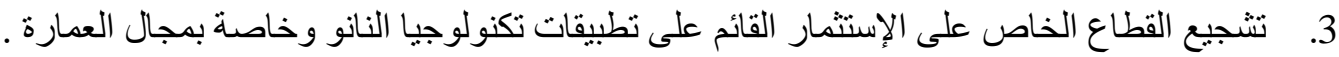

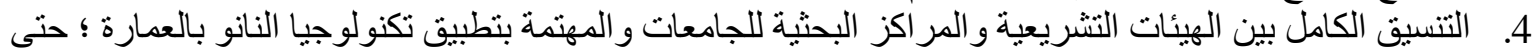

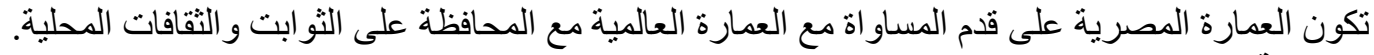

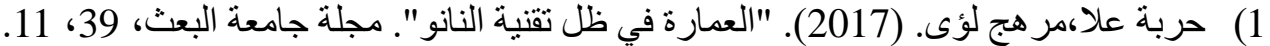

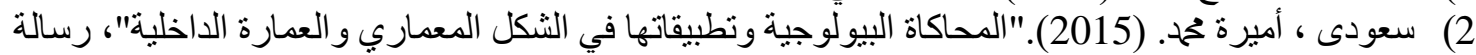

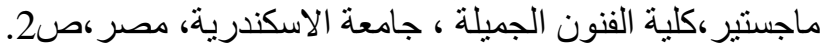

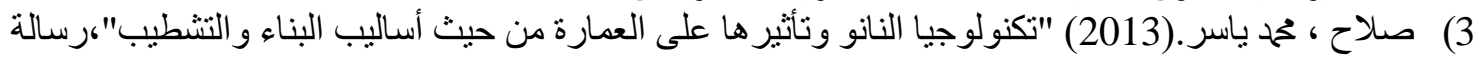

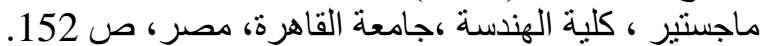

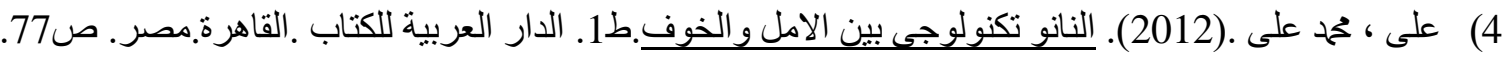

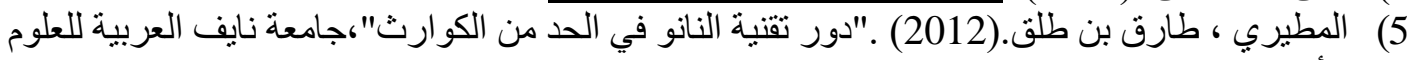

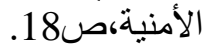
6) الاسكندر انى، شريف (2010). تكنولوجيا النانو من أجل غدأفضل. ط1. المجلس الوطنى للثقافة والفنون و الآداب. الكويت ،صنا20) 7) سلامة ، صفات. (2009) .النانو تكنو لوجى عالم صغير ومستقبل كبير (مقدمة في فهم علم النانوتكنولوجى). ط1. الدار

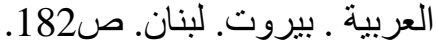

8) دوناتو رومانو. (2003). الاقتصاد البيئى والتنمية المستدامة. المركز الوطنى للسياسيات الزر اعية. سوريا.ص3

\section{REFERENCES}

9) Mohamed, A. (2015)." Nano-Innovation in Construction, A New Era of Sustainability". In International Conference on Environment and Civil Engineering (Vol. April, pp. 97-100108). Pattaya- Thailand.

10) Sev, A., \& Ezel, M. (2014). "Nanotechnology innovations for the sustainable buildings of the future". World Acad Sci Eng Technol Int J Civil Environ Struct Constr Architectural Eng, 8(8), 886-896.

11) Elsamny, M. (2013). "Biological Nano Architecture: Architecture in the Age of Biomaterials". In Advanced Materials Research (Vol. 671, pp. 2174-2179). Trans Tech Publications.

12) Sasmal, S., Bhuvaneshwari, B., \& Iyer, N. R. (2013). "Can Carbon Nanotubes Make Wonders in Civil. Structural Engineering", vol. 2, pp. 117-129.

13) Lu, L. Y., Lin, B. J., Liu, J. S., \& Yu, C. Y. (2012). "Ethics in nanotechnology: What's being done? What's missing"? Journal of business ethics, 109(4), pp. 583-598.

14) Nasibulin, A. G., Shandakov, S. D., Nasibulina, L. I., Cwirzen, A., Mudimela, P. R., Habermehl-Cwirzen, K., ... \& Tian, Y. (2009). "A novel cement-based hybrid material." New Journal of Physics, 11(2), 023013. 
15) Kim, J. J., \& Haghighat, F. (Eds.). (2009). "Sustainable Built Environment”. Volume I. United Kingdom. Eolss Publishers.

16) Allhoff, F., Lin, P., \& Moore, D. (2009). What is nanotechnology and why does it matter?: from science to ethics. John Wiley \& Sons.

17) Zhao, Z., \& Gou, J. (2009). Improved fire retardancy of thermoset composites modified with carbon nanofibers. Science and technology of advanced materials, 10(1), 015005.

18) Morris, J., \& Willis, J. (2007). US Environmental Protection Agency "nanotechnology white paper". p. 136,US Environmental Protection Agency, Washington, DC.

19) Lányi, E. (2007). The basic principles of sustainable architecture. Periodica Polytechnica Architecture, 38(2), 79-81.

20) Cam, C. N., \& Ong, B. L. (2005, September). Building environmental assessment tools and the multidimensional pathways towards sustainable architecture. In Proceedings of the 2005 world sustainable building conference (SB05Tokyo) (pp. 27-29).

21) Huhtala, M., Kuronen, A., \& Kaski, K. (2002). Carbon nanotube structures: molecular dynamics simulation at realistic limit. Computer Physics Communications, 146(1), 30-37.

\section{Websites}

\section{2) WBDG Whole Building Design Guide."(2016) "Sustainable" |} http://www.wbdg.org/design-objectives/sustainable

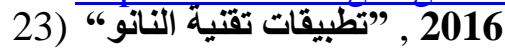
http://www.wikipedia.org/wiki/

24) M. Ball,( 2015) "Carbon Nanotube Applications: Ready for a Space Elevator?" https://www.autodesk.com/redshift/carbon-nanotube-applications/.

25) "Vincent Callebaut Architectures - Project - HYDROGENASE," 2014. http://webcache.googleusercontent.com/search?q=cache:http://archello.com/en/project/hy drogenase \&num $=1 \&$ dcr $=0 \&$ strip $=1 \&$ vwsrc $=0$.

26) "Biological architecture" 2011 http://createyourcosmos.blogspot.com.eg/2011/09/biological-architecture.html.

27) "HYDROGENASE proj Vincent Callebaut." http://vincent.callebaut.org/object/100505_hydrogenase/hydrogenase/projects/user.

28) "jubilee-church" http://www.arcvision.org

29) "Energy Consumption World Wide." https://www.confusedaboutenergy.co.uk/index.php/climate-and-the-environment/56energy-consumption-world-wide. 